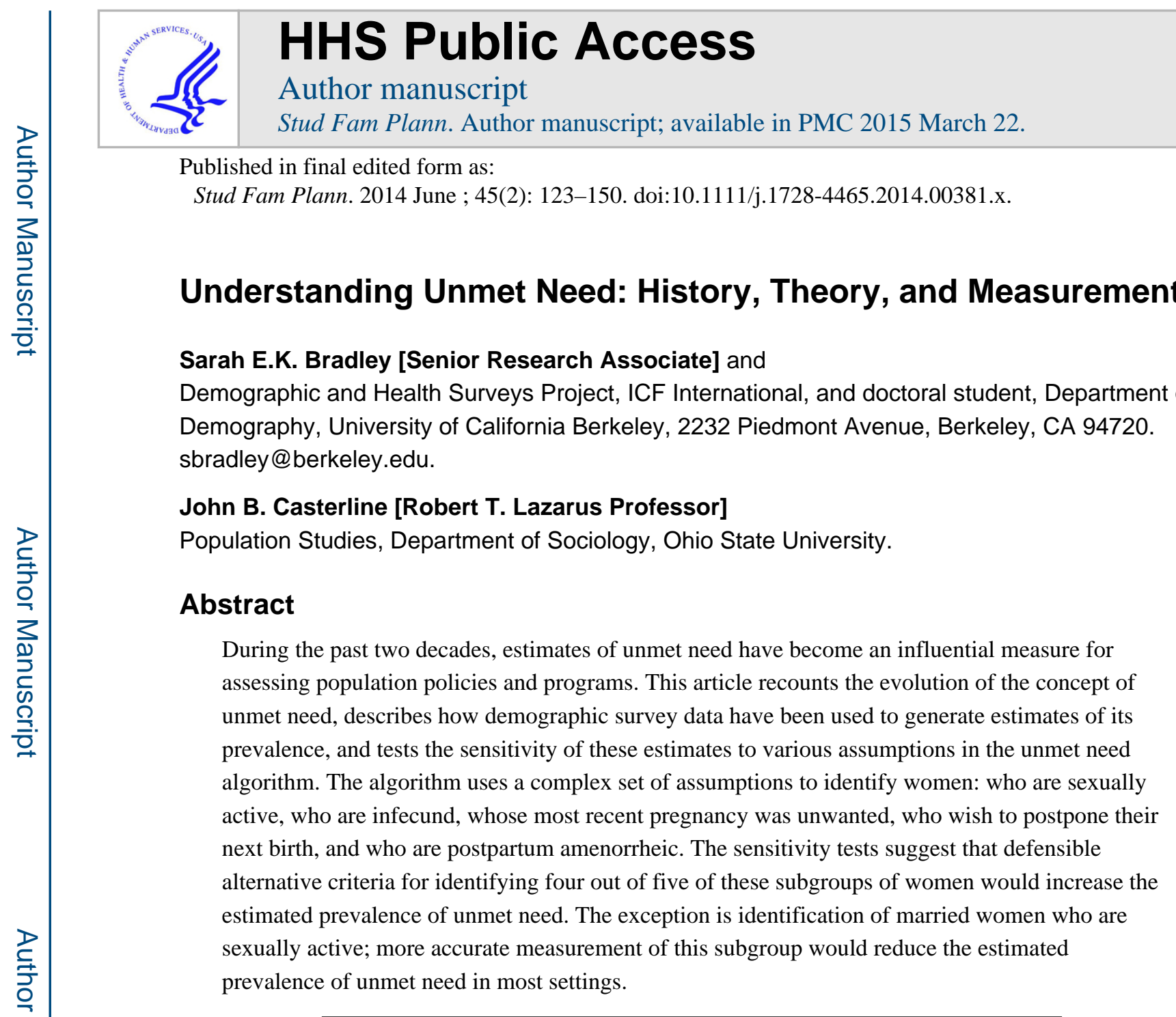

Unmet need for family planning, which refers to the condition of wanting to avoid or postpone childbearing but not using any method of contraception, has been a core concept in the field of international population for more than four decades (Robey, Ross, and Bhushan 1996). The concept is used for a wide variety of purposes: to estimate the number of women with unmet need worldwide as a rationale for increased investment in family planning programs; to evaluate national family planning programs and measure progress toward Millennium Development Goal (MDG) 5b (the achievement of universal access to reproductive health); and as a conceptual bridge between concerns regarding population growth and the inability of women and couples to achieve their reproductive goals without coercion.

The concept of unmet need has also been misused and misunderstood. Often asserted is that estimates of unmet need represent the proportion of women who want to practice contraception but are prevented from doing so by inadequate access to supplies and services. As we demonstrate below, however, the standard algorithm does not include any direct measures of the desire to practice contraception or any direct measures of access to contraception. Unmet need has been interpreted—and has been criticized—as an individual- 
level measure of survey respondents' current need for family planning. This misinterpretation has led to critiques that seem justified-for example, how can a pregnant woman have unmet need? As we explain below, an understanding of the history, definition, and appropriate interpretation of unmet need ameliorates these concerns.

Whereas the concept of unmet need-the discrepancy between women's fertility preferences and contraceptive use-is straightforward, the measurement of unmet need is challenging. Estimating unmet need from survey data requires multiple assumptions concerning women's exposure to the risk of pregnancy, sexual behavior, physiological capacity to become pregnant, and the reliability of retrospective reporting. In this article, we conduct empirical analyses of the sensitivity of estimates of unmet need to such assumptions, and we consider how much estimates of unmet need change when other, arguably equally valid, assumptions are employed. These sensitivity tests constitute the bulk of this article and they yield some striking results: the estimated prevalence of unmet need would be markedly higher, or lower, if existing assumptions were replaced by entirely defensible alternative assumptions. The sensitivity analysis has the virtue of not only indicating the direction of impact—which for the most part is obvious a priori-but also quantifying the magnitude of impact.

This article reviews the history of the concept of unmet need and its changing rationale as the family planning movement underwent transformation during the past four decades. We trace the development of ever-more-complex algorithms for estimating unmet need using survey data, followed by a discussion of the algorithm that is currently standard in analysis of Demographic and Health Survey (DHS) data-the outcome of a 2012 revision. We discuss the goals and logic of estimating unmet need and address misunderstandings that have resulted in misuse of these estimates and off-the-mark critiques. We also present a series of simulations testing the sensitivity of unmet need estimates to assumptions made in the DHS algorithm, comparing estimates from the standard algorithm to estimates calculated using alternative assumptions.

\section{HISTORICAL BACKGROUND1}

Under the label "KAP-gap," the concept of unmet need for family planning had its origins in the first fertility and family planning surveys carried out during the 1960s. From this era to the present, a fundamental question underlying the formulation of population policy has been the extent of unintended fertility and, correspondingly, the amount of unsatisfied demand for fertility regulation, which is crucial to determining strategies to reduce high fertility. Over the years, economists (e.g., Kelley 1988; Pritchett 1994) and demographers (e.g., Davis 1967; Hauser 1969) have questioned whether sufficient unsatisfied demand for fertility control existed in high-fertility countries to warrant a family planning services—or "supply-side" - approach to reducing population growth rates.

To address this skepticism and to determine the extent of demand for fertility regulation, surveys of knowledge, attitudes, and practices (KAP) regarding family planning were mounted in various parts of the developing world in the 1960s. These "KAP surveys"

\footnotetext{
${ }^{1}$ This section of the article draws heavily from Casterline and Sinding 2000.
} 
(Bogue 1974) showed that in nearly all societies a discrepancy existed between some women's reproductive preferences and their contraceptive behavior-that is, a "KAP-gap" existed (Mauldin 1965; Berelson 1969). The identification of the KAP-gap was an important milestone in the development of population policies and programs through the 1960s, particularly in Asia. The documented existence of a significant group of women who expressed desire to limit fertility and who ostensibly would use family planning services if available inspired many governments to initiate ambitious family planning programs.

On the basis of analysis of women's responses to three KAP surveys in Taiwan, Freedman and colleagues (1972) first identified a subset of women who they argued would be receptive to practicing contraception without changing their fertility desires because they indicated a wish to terminate childbearing but reported no practice of contraception. Two years later, Freedman and Coombs (1974) used survey data from several countries to generate estimates of the size of this group. Drawing on the social psychology literature, they called the gap between the "need" for family planning and its use "discrepant behavior."

The successor to the KAP surveys of the 1960s was the World Fertility Survey (WFS) program. The WFS began in 1972, ran through 1984, and encompassed surveys in 41 developing countries. The WFS collected pertinent information, but generating KAP-gap estimates was viewed as secondary to the goal of providing sound estimates of vital rates (fertility and mortality), the proximate determinants of fertility, and even fertility preferences. None of the 40 "comparative studies" produced by the WFS examined the relationship between fertility preferences and contraceptive use. (The WFS did, however, devote systematic effort to the estimation of unwanted fertility [Lightbourne 1985].) Greater attention was given to the relationship between preferences and contraceptive use in analyses of data from surveys conducted through the Contraceptive Prevalence Surveys (CPS) project, which ran from 1978 to 1984 (Anderson and Morris 1981; Morris et al. 1981).

When the first set of WFS surveys from Asia became available, Westoff (1978) produced a five-country study of "unmet need for family planning," the phrase he substituted for "KAPgap." Consistent with the dominant concerns in international population during the 1960s and 1970s, Westoff identified the target audience for this indicator as "developing-world countries that wish to curb excessive rates of population growth" (Westoff 1978: 173). This WFS study was the first of several conducted by Westoff and his colleagues as they strove to develop more refined measures of the discrepancy between fertility preferences and contraceptive use.

The Demographic and Health Survey program, which succeeded the WFS and CPS, has conducted nationally representative surveys in 91 countries from 1984 to the present. The DHS became a vehicle for consolidating these refinements in the measurement of unmet need and adding further refinements, as explained in a series of comparative reports (Westoff and Ochoa 1991; Westoff and Bankole 1995; Westoff 2001 and 2006; Bradley et al. 2012). The DHS investment in measuring unmet need for contraception-the care taken in developing intricate algorithms and their application in numerous country and 
comparative reports-is indicative of the increasing importance that the population and reproductive health field has attached to unmet need and related concepts. The contraceptive prevalence rate (CPR) remains the parameter of first interest regarding contraception in most quarters, but as time has passed, the prevalence of unmet need has assumed almost equal stature. Because unmet need joins together contraceptive behavior and fertility preferences, the concept represents a marked shift in emphasis toward a focus on meeting individual families' reproductive intentions and away from national program goals to "curb excessive rates of population growth" (Westoff 1978: 173).

As preparations began for the 1994 International Conference on Population and Development (ICPD) in Cairo, Egypt, advocacy groups for women's health and rights, which had grown in size and determination during the previous two decades, set about using the ICPD as a means of shifting the focus of population programs from demographic goals and targets to women's lives, including but not limited to their reproductive health (Sen et al. 1994; McIntosh and Finkle 1995). The manifesto of this movement became the 1994 "Women's Declaration on Population Policies," one of whose main planks was the elimination of demographic targets, quotas, and goals. These demographically derived targets, it was argued, led to programs that frequently directed women into undesired contraception and inappropriate methods of family planning and, in their worst manifestations, resulted in coercing women to undergo sterilization or abortion (GarciaMoreno and Claro 1994). As it turned out, the concerted effort to redefine the principles underlying international population policies and programs was largely successful, as clearly reflected in the ICPD Programme of Action agreed to by more than 180 governments in 1994 (McIntosh and Finkle 1995).

In retrospect, the preparations for the Cairo ICPD and the conference itself marked a historic redirection for the field. Ironically, in the highly charged political context of the early 1990s, the concept of unmet need for family planning — which had its origins in the mainstream population-control movement of the 1960s and 1970s—assumed a new function as a bridge between the demographic and reproductive health points of view. From the standpoint of women's reproductive rights, unmet need was taken as one indicator of the violation of such rights and one of several basic rationales for women's empowerment (McCauley et al. 1994). From the demographic standpoint, analysis published by Sinding and colleagues (1994) indicated that, in nearly all countries that had specified demographic targets, fully satisfying the unmet need for contraception would result in contraceptive prevalence rates that were higher than the established targets. The interpretation placed on this finding was that public policies designed to satisfy existing demand for fertility regulation would obviate the need for targets that, in turn, might be —and had been (see Connelley 2006)—used as justification for activities deemed undesirable on human rights grounds. This conclusion reassured many governments, particularly European governments, that achieving demographic goals without pursuing numbers-driven population policies was possible. In the ICPD Programme of Action, unmet need for family planning receives explicit mention as a core rationale for population programs. The document goes on to say that "governmental goals for family planning should be defined in terms of unmet needs for information and services" and that "all countries should, over the next several years, assess the extent of national unmet need 
for good-quality family-planning services" (United Nations 1994: paragraphs 7.12 and 7.16).

Casterline and Sinding (2000) speculated that unmet need's salience in the international population arena had reached its height in the late 1990s and was beginning to decline because, among other reasons, of diminishing emphasis on family planning. This forecast has proven incorrect; family planning has enjoyed a revival during the past decade as an international priority (Cleland et al. 2006; Bongaarts et al. 2012; Darroch and Singh 2012; Cleland and Shah 2013; Peterson, Darmstadt, and Bongaarts 2013). As would be expected, unmet need has accompanied family planning as a priority, as reflected in the selection of unmet need in 2006 as one of three reproductive indicators for MDG 5b: the achievement of universal access to reproductive health. One could argue that the concept of unmet need has never had higher standing on the international population agenda than at present.

\section{ESTIMATING UNMET NEED FROM DEMOGRAPHIC SURVEY DATA}

Attempts to quantify levels of unmet need have grown more demographically sophisticated during the past four decades, and accordingly more complex to calculate. Drawing upon Bradley and colleagues (2012), we recount how unmet need estimation methods have changed over time, describe the current algorithm applied to DHS data, and reflect on the goals and rationale for estimating unmet need from survey data.

\section{Evolution from the Late 1970 s to 2010}

Westoff's (1978) first effort to estimate unmet need using WFS data employed a straightforward definition: among currently married women of reproductive age (the denominator), the proportion who want no more children but are not practicing contraception (the numerator). This definition was expanded to encompass "unmet need for spacing" (women who do not wish to become pregnant within two years but are not practicing contraception) for application to the few WFS surveys that asked about women's desires to postpone, not just avoid altogether, a next birth (Westoff and Pebley 1981; Nortman 1982).

Westoff's first straightforward algorithm excluded pregnant and postpartum amenorrheic women on the grounds that this set of women had no immediate need for contraception. Treatment of pregnant and postpartum amenorrheic women was one of a number of definitional issues that soon came to the fore. Subsequently, Westoff and Pebley (1981) showed that different definitions of unmet need (12 different definitions were specified) produced estimates of the prevalence of unmet need that varied substantially (see also ElZeini 1999). A further broadening of the definition was advocated by Nortman, who argued that some pregnant, breastfeeding, and amenorrheic women should be included in the definition of unmet need because many would require contraception as soon as their current ineligible status changed (Nortman 1982; Nortman and Lewis 1984).

Some of these recommendations were incorporated in the algorithm for estimating unmet need using DHS data developed in the late 1980s (Westoff 1988). The DHS asks women who want more children how soon they want to have the next birth. The DHS also asks 
pregnant and postpartum amenorrheic women whether their current or most recent pregnancy was wanted then, later, or not at all. Westoff's new algorithm was distinctly more complicated than prior algorithms, chiefly because of the inclusion of pregnant and amenorrheic women as having unmet need if their current or most recent pregnancy was unwanted or mistimed (Westoff 1988). The argument for this treatment of pregnant and postpartum amenorrheic women is straightforward enough: some of these women are in this state at the time of the survey because they were not practicing contraception even though they did not want to become pregnant. That is, if the goal is to estimate the proportion of women who ought to be practicing contraception if their reproductive goals are to be met, then pregnant and postpartum amenorrheic women should be taken into account. ${ }^{2}$

Further complexity in the algorithm was introduced by the decision to identify infecund women-women incapable of becoming pregnant - and exclude them from the numerator in the estimation of unmet need. The justification for this exclusion is twofold: at the aggregate level, contraceptive use by this subgroup has no bearing on the level of fertility; and at the individual level, contraceptive use has no effect on the risk of an unintended pregnancy. Identifying infecund women in survey data is difficult, however. Multiple and increasingly complicated rules have been employed. The first attempt identified women as infecund if they were not pregnant or postpartum amenorrheic but had not menstruated in the last 6 weeks (Westoff 1988). This cutoff was successively increased to 12 weeks (Westoff and Ochoa 1991) and then 6 months (Westoff and Bankole 1996). Further criteria for identifying those who were infecund were (a) not having given birth in the five years preceding the survey despite having been married for more than five years and never practicing contraception (Westoff 1988); (b) self-reporting being menopausal or, when asked if they wanted a/another child, replying "unable to get pregnant" (Westoff and Bankole 1995); and (c) self-reporting a hysterectomy.

With these key features established - the coding of pregnant and postpartum amenorrheic women and the identification of infecund women - this algorithm in various formulations has been applied to all rounds of DHS surveys from Phase II (which began around 1990) to the present. The resulting estimates have been presented in the survey-by-survey reports and in periodic comparative studies (Westoff and Ochoa 1991; Westoff and Bankole 1995; Westoff 2001, 2006, and 2012; Bradley et al. 2012). The algorithm was modified further over the years, adding complexity to the determination of which women have unmet need. Some DHS surveys included a three- or five-year contraceptive calendar. This allowed for identification of contraceptive failures (which were given separate treatment in the unmet need algorithm) and provided yet another basis for identification of infecund women. Making use of calendar data, however, had the undesirable effect of generating unmet need estimates that were not able to be directly compared with prior estimates in the same country (see Bradley et al. 2012). Furthermore, in some phases of the DHS, respondents were asked the following two questions: "If you became pregnant in the next few weeks, would you be happy, unhappy, or would it not matter very much?" and "In the next few weeks, if you discovered that you were pregnant, would that be a big problem, a small problem, or no

\footnotetext{
${ }^{2}$ At the extreme, if there were no waiting time to conception, all women with unmet need would be pregnant or postpartum amenorrheic all the time.
} 
problem for you?" The unmet need algorithm was refined to take this information into account. With the accumulation of these modifications, the algorithm became far more complex, and comparability within a country and across countries was compromised. These negative attributes, combined with the increasing importance attached to unmet need (e.g., its elevation to an MDG indicator), led to a decision in 2010 to develop a simplified algorithm that could be implemented in the widest set of surveys, not only DHSs but also UNICEF's Multiple Indicator Cluster Surveys (MICSs).

\section{2-Revised Algorithm}

The revised algorithm was devised by MEASURE DHS staff, drawing on advice from a group of technical experts and staff from USAID and UN agencies (Bradley et al. 2012; MEASURE DHS 2013). The overarching goal was to devise an algorithm that, while maintaining the principles underlying the algorithm that evolved during the 1990s and 2000s, was less elaborate and required a core set of input variables available in the maximum number of surveys.

The revised algorithm uses items provided by every DHS survey conducted since 1990 . This led to dropping inclusion of calendar data and of items asking how happy a woman would be if she became pregnant soon and how much of a problem a pregnancy would be. Identification of infecund women was modified to allow for harmonization with surveys other than the DHS. The duration for which women are considered postpartum amenorrheic - and thus assigned an unmet need status based on retrospective rather than prospective fertility preferences—was set at 24 months (as against 60 months in previous algorithms).

A common misconception is that unmet need is assessed simply by asking women whether/ when they want to become pregnant and whether they are currently practicing contraception (MEASURE DHS 2013). Unmet need, defined as the "gap" between women's fertility preferences and contraceptive use, would seem to require no more than this. A demographically smart algorithm should, however, also take into account pregnant and postpartum amenorrheic women, which leads to reliance on reports of the wantedness of the most recent pregnancy. Infecundity also warrants attention. In the end, even the simplified algorithm developed in 2010-11 requires 15 survey items (see Appendix A of Bradley et al. 2012).

The denominator, or universe, for unmet need is conventionally currently married/in-union women, under the assumption that these women are sexually active. In some applications, the denominator includes unmarried women who are sexually active, defined as those who report having had sex in the 30 days preceding the survey. The sample of sexually active women is then separated into current contraceptive users and nonusers. Current users are categorized as having "met need for limiting" if they are sterilized or if, when asked whether they want additional children, say they want no more or that they cannot become pregnant. ${ }^{3}$ All other contraceptive users are considered to have "met need for spacing."

\footnotetext{
${ }^{3}$ Women practicing contraception are classified as having met need rather than as infecund even if they also say they cannot become pregnant.
} 
For women not currently practicing contraception, the algorithm checks whether they are currently pregnant or whether their menstrual period has not returned since the birth of their last child. If they are either pregnant or postpartum amenorrheic following a birth during the two years preceding the survey, they are categorized according to the stated wantedness of the current pregnancy or most recent birth. If they indicate that the pregnancy was not wanted, they are classified as having "unmet need for limiting." If they indicate the pregnancy was wanted but occurred earlier than preferred, they are classified as having "unmet need for spacing." If they indicate that the pregnancy was wanted at that time, they are classified as having "no unmet need."

The algorithm considers whether women who are not currently practicing contraception and not pregnant or postpartum amenorrheic should be classified as infecund. The three criteria are: (1) married five or more years, have not had children in the past five years, and have never practiced contraception; (2) no menstruation during the preceding five years; and (3) self-report of inability to become pregnant, "menopausal," or "had a hysterectomy" in response to one of several survey items.

Finally, women who have not been captured by any of the preceding rules are classified according to their responses to questions concerning whether and when they want any (more) children. Women who want no more children are considered to have "unmet need for limiting"; those who want children two or more years in the future, or are undecided whether/when they want a child, are considered to have "unmet need for spacing"; and those who want children within the next two years have "no unmet need."

\section{Goals and Logic of the Unmet Need Estimator}

The fundamental goal of all of the unmet need estimators developed from the 1970s to the present is to estimate the amount by which contraceptive prevalence would increase if fertility preferences were fully implemented. Or, stated differently, the goal is to estimate the proportion of women who, according to their stated fertility preferences, ought to be practicing contraception at the time of the survey but are not. Note that the goal is an aggregate-level estimate. This estimate is created via a one-by-one classification of women, but this individual-level exercise is carried out to obtain a meaningful aggregate-level estimate. The estimate itself is hypothetical, a counterfactual: at the population level, how much would contraceptive prevalence increase if all women perfectly implemented their current fertility preferences? Moreover, this hypothetical amount does not rely on women's expression of a desire to practice contraception; rather, need for contraception is inferred by comparing stated preferences and reported contraceptive behavior.

Recognizing that an aggregate-level estimate is the fundamental goal and that the unmet need algorithm is not intended as a mechanism for identifying individual women in need of contraception deflects many of the most common critiques of unmet need estimates (which have the effect of casting doubt on the validity of the concept itself). For example, some have questioned how it can be that some pregnant women (those with a mistimed or unwanted pregnancy) are classified as having unmet need (Pritchett 1994). This assignment is indeed illogical if the goal is to classify every woman in terms of her need for contraception at the time of the interview: pregnant women are not immediately at risk of 
becoming pregnant. This feature of the unmet need algorithm in the DHS, however, is entirely defensible - indeed, it is one of its strengths- when the goal is to quantify the amount by which contraceptive prevalence among all reproductive-age women would increase if fertility preferences were fully and perfectly implemented.

It also follows that the DHS's unmet need algorithm is not designed to serve as a screening tool for family planning service providers. One can imagine developing such a tool: the woman's fertility preference (i.e., whether she wants to avoid pregnancy, at least in the short-term), exposure to the risk of pregnancy, and current fecundity status would need to be assessed. An individual-level unmet need measure would also need to consider a woman's explicit desire to practice contraception, a factor not considered at all in the standard unmet need algorithm. We wish to underscore the essential point that the DHS's unmet need algorithm - the outcome of extensive effort by researchers from the late 1970s to the present - is designed to produce a national-level demographic estimate, not to guide day-to-day family planning service provision at the individual level. Moreover, inadequacy in serving this end does not imply deficiencies in the algorithm's suitability for its intended goal of generating aggregate-level demographic estimates.

Recognizing the goals and logic of the algorithm also leads to concern regarding the common practice in the research community of using the unmet need variable produced by the algorithm in individual-level multivariate analysis. This variable is included in the DHS's standard recode file. Therefore, without any extra programming effort, researchers can examine differentials in unmet need according to demographic and socioeconomic variables in tabular or regression analysis. But whereas the variable does assign all women an unmet need status, for a large subset of women - those who are pregnant or postpartum amenorrheic (approximately one-fourth of married women of reproductive age ${ }^{4}$ )—-their unmet need status was acquired as much as 33 months earlier (i.e., amenorrheic women who are 24 months postpartum). The wantedness status of a pregnancy that occurred nearly three years ago may not accurately reflect women's fertility intentions at the time of the surveyfor example, if a postpartum amenorrheic woman's prior child was wanted but now she does not want another child anytime soon or at all. One must assume that the effect of explanatory variables remains stable over this time period. Depending on the variables of interest and the complexity of the multivariate analysis (i.e., the sample size in explicit or implicit subgroups), this may not be a tenable assumption. Certainly those who contemplate conducting individual-level research on unmet need should be cognizant of the stability assumption and evaluate its validity - as well as the validity of other assumptions inherent in the algorithm — given the set of explanatory variables of interest. In addition, analyses focusing on subgroups of women-for example, unmarried or postpartum women-should recognize that assumptions about these subgroups can have sizable effects on levels of unmet need, as estimated below.

\footnotetext{
${ }^{4}$ In the 60 DHSs that we analyze below, the percentage of married women who were pregnant or postpartum amenorrheic at the time of the survey varies widely, from 5 percent in Albania to 48 percent in Chad. On average, one-third of women in sub-Saharan Africa and 10-15 percent of women in other regions were pregnant or postpartum amenorrheic when interviewed.
} 


\section{SENSITIVITY OF UNMET NEED ESTIMATES TO DEMOGRAPHIC ASSUMPTIONS}

In this section, we test the sensitivity of unmet need estimates to assumptions made in the DHS algorithm, using the most recent survey from each of the 60 countries that have conducted a DHS since 2000. The vast majority of these surveys are recent; half of the surveys analyzed were conducted in 2010 or later. We first calculate the standard estimate (using the 2012 revised algorithm) of unmet need among currently married women. Except where noted, all estimates are for married women aged 15-49 for purposes of comparability across surveys, several of which excluded unmarried women. ${ }^{5}$ We then compare this value to estimates calculated under alternative assumptions.

\section{Sexual exposure}

In the standard algorithm, currently married women are assumed to be exposed to the risk of pregnancy even if they say they are not practicing contraception because their husband is away or because they have no or infrequent sex. We measure how much the estimate of unmet need would change under the assumption that such women do not, as they state, need contraception.

Whereas married women are assumed to be regularly exposed to the risk of pregnancy, the opposite (no exposure) is assumed for unmarried women unless they say they have had sex in the 30 days preceding the survey. We suspect this underestimates unmet need among unmarried women, and we test the impact of assuming substantially more sexual activity among such women (specifically, two times as much). ${ }^{6}$

\section{Infecundity}

To determine which women are physiologically capable of bearing children, the unmet need algorithm infers biological information from the limited available behavioral data. Drawing on previous research demonstrating that one criterion (containing three components: that women who were first married five or more years ago, had no children in the past five years, and have never practiced contraception) likely overestimates the number of infecund women, we calculate changes in estimates of unmet need if some of these women were considered fecund. 7

\footnotetext{
${ }^{5}$ The surveys for Bangladesh, Egypt, Jordan, Maldives, Pakistan, Turkey, and Vietnam interviewed only ever-married women, thus precluding calculation of unmet need among unmarried women. Additionally, the India and Morocco surveys did not ask nevermarried women all questions needed to calculate unmet need. In Table 2, surveys in which fewer than 50 (unweighted) unmarried women reported sexual activity in the last 30 days are also excluded to ensure that results are reliable.

${ }^{6}$ We also conducted the same analysis classifying women as sexually active if they had sex in the three months prior to interview rather than in the 30 days prior. Unmet need among unmarried women was higher using this classification, but the impact of doubling the number of sexually active unmarried women in the population remained quite small when unmet need was estimated among all sexually active women.

${ }^{7}$ Many of the women classified as infecund based on this criterion are also classified as infecund based on the other criteria specified earlier. In this analysis, we simply remove the specified criterion, allowing women to be classified as infecund based on other criteria, or as potentially in need of contraception.
} 


\section{Retrospective reporting of fertility preferences}

For pregnant and postpartum amenorrheic women, classification of unmet need is based, in part, on retrospective reports of whether their current or most recent pregnancy was intended. These retrospective reports are likely downwardly biased (Casterline and El-Zeini 2007). We test how much estimates of unmet need would increase with the use of Casterline-El-Zeini estimates of unwanted fertility, which typically are higher than the retrospective estimates.

\section{Timing of future fertility preferences}

Fecund women are assumed to have no need for contraception if they want a child within the next two years. However, such women are arguably in need of contraception for at least an additional year if they truly want to postpone the next birth by at least two years. We therefore produce estimates of levels of unmet need wherein women who want to postpone the next birth one year are reclassified as having need for contraception. ${ }^{8}$

\section{Duration of postpartum amenorrhea}

In the standard algorithm, women who are post-partum amenorrheic are assumed not to be at risk of pregnancy and, as described below, their unmet need status is based on the wantedness of their most recent pregnancy. How long a postpartum woman should be considered protected from the risk of pregnancy is, however, unclear. The current algorithm allows the protection to extend to 24 months. Clinically, however, women are generally considered at risk of pregnancy after 6 months postpartum even if their period has not returned. To examine the sensitivity of unmet need estimates to the assumed duration of protection afforded by postpartum amenorrhea, we re-estimate unmet need substituting 6 months duration for 24 months. The consequence is that women who are amenorrheic 7 to 24 months postpartum are classified according to their prospective fertility preferences rather than the wantedness of the recent birth. ${ }^{9}$

With each test, our goal is to obtain what might be regarded as a maximum reasonable impact of adopting an alternative assumption. For example, in the first sensitivity test, we assume that all married women who say they have no or infrequent sex cannot have unmet need. In reality, some of these women probably have sex frequently enough to be at risk of pregnancy, and hence the "true" level of unmet need likely lies somewhere between the standard estimate and the alternative used in our sensitivity test. The purpose of these sensitivity tests is to establish what might be regarded as outer bounds - that is, the maximum amount by which unmet need would change if certain crucial ingredients were measured differently.

\footnotetext{
${ }^{8}$ Arguably, one year is too short of a time horizon. More reasonable cutoffs might be 15 or 18 months. The vast majority of women (greater than 99 percent in every survey), however, provided a response to the question "How long would you like to wait from now before the birth of (a/another) child?" in completed years (one, two, and so forth) or in months that did not fall between 12 and 24 . In practical terms, therefore, the alternatives are one or two years.

${ }^{9}$ In this analysis, we lowered the threshold for classification as postpartum amenorrheic from 24 to 6 months and put women previously classified as postpartum amenorrheic for 7 to 24 months through the algorithm again. As such, some of these women were classified as infecund if they said they are now menopausal, had a hysterectomy, or are unable to become pregnant. Otherwise, they were classified as fecund and assigned an unmet need status on the basis of their prospective preferences.
} 
We summarize results across 60 nationally representative surveys by calculating unweighted averages for each of the five geographic regions shown in Table 1. Note that these regional averages are unweighted means of the estimates from the surveys in the region, taking no account of the relative population size of each country. For example, Ethiopia and Lesotho are each included in the East and Southern Africa regional average as one observation, thus being given the same relative weight despite the fact that the former's population is more than 40 times larger than the latter's. We adopt this approach because in most regions the DHS surveys do not represent a sufficient proportion of the entire population of the region to provide a basis for estimates for the region's population.

\section{Sexual Exposure}

In principle, only those women who are sexually active should be classified as having unmet need. However, distinguishing sexually active and inactive women in survey data is difficult for two reasons. First, sexual behavior is a sensitive subject, and survey inquiry may often yield invalid information. Second, it is unclear what frequency of sexual activity justifies contraceptive protection.

We first consider currently married women. As described above, the algorithm employed during the past 25 years has assumed that all currently married women have sufficient sexual exposure to justify contraception if they wish to avoid pregnancy (temporarily or indefinitely). On average this assumption largely holds true; most married women are regularly exposed to the risk of pregnancy. Some currently married women, however, are sexually inactive - as a matter of terminal abstinence or, especially in countries having large populations of labor migrants, because their husbands are away for extended periods. Such women are unlikely to consider themselves to be in need of contraception. Indeed, they tend to respond to the survey item regarding "reason for not practicing contraception" with "no sex" or "infrequent sex." If we treat these responses as reflecting a lack of need for contraception, we can assess the extent of overestimation of unmet need resulting from inclusion of these women by calculating unmet need with these women excluded from the numerator. ${ }^{10}$

Table 1 presents country-by-country findings and regional averages reflecting these definitional distinctions. On average, the estimated percentage of currently married women having unmet need drops by 3.4 percentage points when this set of women is excluded from the unmet need category. This is a 16 percent decrease in unmet need on average, which is substantial. The impact is relatively uniform across regions, but this disguises far greater variation across countries: 5 percentage points or greater in 9 countries, and less than 2 percentage points in 16 countries. The impact is greatest in those countries having high levels of labor migration and/or terminal abstinence at relatively young ages; the most notable cases are Nepal (17.5 percentage point decrease) and Bangladesh (6.2 percentage point decrease). These differences are large, but it should be noted that some of the married women who report infrequent or no sexual activity may have sex in the near future. The unmet need estimates drawn from our alternative assumption, therefore, underestimate

\footnotetext{
10 If we instead use reported time since sexual activity for this test (i.e., classifying all married women who have not had sex in the past 30 days as having no need), the results are largely similar.
} 
unmet need. We posit, however, that the extent of error in the form of underestimation is less than the extent of error in the form of overestimation that occurs when all married women are assumed to be sexually active.

Next we consider unmarried women. General agreement exists that unmet need is a relevant concept for unmarried women, conditional on their sexual exposure. In most DHS surveys, an effort is made to ascertain sexual activity among unmarried women by asking how recently they have had sex. In the 2012 revision of the unmet need algorithm, unmarried women are considered at risk of pregnancy if they report having had sex during the 30 days preceding the survey, and we can examine the resulting estimated levels of unmet need (for unmarried women and for all women of reproductive age). Before doing so, we pause to ask whether this criterion is a sound basis for identifying sexually active women. We suspect, for two reasons, that this criterion is likely to miss unmarried women with unmet need for contraception. First, young unmarried women in most societies are likely to underreport their sexual activity, especially if interviewed in their parents' home. Second, unmarried women may have a need for contraceptive protection sometime soon even if they have not had sex during the past 30 days.

Estimates using the standard algorithm of unmet need among unmarried sexually active women are shown in Table 2. A fundamental feature of Table 2 is that unmet need is substantially higher-approximately 50 percent higher-among unmarried sexually active women than among currently married women (as in Table 1); the global country averages are 32 percent and 21 percent, respectively. Table 2 also presents unmet need estimates for all sexually active women of reproductive age, pooling together married and unmarried women. Note that to isolate the effect of assumptions concerning unmarried women, we retain the standard assumption that all married women are sexually active. To examine the sensitivity of unmet need estimates to possible underenumeration of sexually active unmarried women, we conduct the following test. We suppose that there were two times as many sexually active unmarried women, and that these women had the same prevalence of unmet need as estimated by the standard algorithm. As shown in Table 2, this modification has a relatively trivial effect on the estimated level of unmet need among all sexually active women of reproductive age-the average increase in 43 countries is only 0.5 percentage points. This reflects the fact that sexually active unmarried women are a small proportion of all women aged 15-49, and hence doubling this proportion has little impact on unmet need estimates in the majority of countries. In only 7 out of 43 countries does the percentage of women with unmet need increase by 1 percentage point or more under this inflation assumption.

From this investigation of the sensitivity of unmet need estimates to measurement of sexual exposure, we draw the following conclusions. First, inclusion of sexually inactive married women in the unmet need category results in overestimation of unmet need to a meaningful extent -3.4 percentage points on average and as much as $6-18$ percentage points in certain countries. Second, unmet need is substantially (50 percent, on average) higher among unmarried sexually active women than among currently married women. Third, despite this finding, prevalence of unmet need among all sexually active women of reproductive age is 
not very sensitive to this higher prevalence among unmarried women, even if sexual activity among unmarried women is markedly underreported.

\section{Infecundity}

Identification of women at risk of pregnancy also requires correct identification of the subgroup of women who are infecund. The revised DHS algorithm assumes that women are infecund if they satisfy at least one of three criteria: (1) first married five or more years ago, have not had children in the past five years, and have never practiced contraception; (2) no menstruation during the preceding five years; or (3) self-report of inability to become pregnant, "menopausal," or "had a hysterectomy" in response to one of several survey items. Ascertaining fecundity status is intrinsically very difficult because fecundity is a physiological state that is not directly observable (certainly not by the interviewer and probably not by the respondent, either), and therefore must be inferred from various behavioral signals, none of which is a perfect indicator.

Elsewhere we evaluate these criteria in depth (Casterline and Odden 2014). Here we focus on the criterion that seems most problematic, which is the combination of (a) first married five or more years ago, (b) have not had children in the past five years, and (c) have never practiced contraception. As documented in Casterline and Odden (2014), this criterion results in a nontrivial likelihood of a false positive-that is, classifying women as infecund who are still able to conceive. (This conclusion follows from classifying women as infecund according to these criteria at a moment some years before the survey and tracking their subsequent birth history.) This criterion also contributes a large proportion of the women classified as infecund when the DHS algorithm is applied. For this reason, if this criterion is deemed invalid and dropped from the algorithm, the estimated level of unmet need noticeably increases, as women formerly classified as infecund become eligible for being classified as having unmet need (see Table 3). The overall impact of ignoring this criterion is substantial: a 3.7 percentage-point increase in unmet need on average across 60 countries. Regional variation exists in this average impact, ranging from 2.4 percentage points in Latin America and the Caribbean to 4.6 percentage points in Asia and the Pacific. Even more variation is evident at the country level, ranging from 0.2 percentage points in Peru to 10 percentage points in Timor-Leste. Estimation of unmet need is clearly sensitive to the criteria employed to identify infecund women, and the DHS algorithm relies on criteria that likely results in an underestimation of unmet need.

\section{Retrospective Report of Fertility Preferences}

The key feature of unmet need for family planning that distinguishes it from other possible indicators of contraceptive shortfall, such as the contraceptive prevalence rate, is that it takes women's fertility preferences into account. This makes unmet need dependent on the measurement of fertility preferences, which presents its own challenges. Of particular concern is the retrospective measurement of the wantedness of recent births. The DHS algorithm relies on this measurement because pregnant and postpartum amenorrheic women are classified in terms of their need for contraception at the time they became pregnant. Numerous methodological studies have demonstrated, however, that the retrospective child- 
wantedness items are the least valid of the standard fertility attitude items in the DHS (Casterline and El-Zeini 2007).

The sensitivity of unmet need estimates to reliance on the retrospective reports of child wantedness can be considered by substituting the Casterline and El-Zeini (2007) estimates of the percentage of recent unwanted births. The Casterline-El-Zeini estimator relies on the prospective preference item, which appears to be the most valid and reliable of the standard attitudinal items, and typically the Casterline-El-Zeini estimate of the percentage of recent unwanted births exceeds the retrospective report, as expected if retrospective reporting is biased downward. Note that this is only an examination of the reporting of births as unwanted, whereas the unmet need algorithm makes use of reports of pregnancies/births as either unwanted or mistimed.

Table 5 presents the results of analyses for 60 countries showing how the percentage of currently married women with unmet need for limiting is affected by whichever estimator is used for determining birth wantedness. The wantedness of recent pregnancies/births is relevant for this subgroup, which constitutes, on average, one-fourth to one-third of currently married women in sub-Saharan Africa - a sizable proportion-but on average less than one-sixth in other regions. This proportion sets limits on the impact on unmet need estimates of alternative measures of the wantedness of recent pregnancies/births.

The average impact globally of substituting the Casterline-El-Zeini estimate for the retrospective report is a 1.5-percentage-point increase in unmet need (Table 4). The effect is less than or equal to 0.5 percentage points in 16 countries, and equals or exceeds 3.0 percentage points in 8 countries. ${ }^{11}$ In short, the impact is generally modest (less than 10 percent increase in estimated prevalence of unmet need), but note that this exercise considers underreporting of unwanted births only. Retrospective underreporting of mistimed births undoubtedly is also common in DHS surveys. Were we able to take this into account as well, the effect on unmet need estimates of bias in retrospective reports of the planning status of births would be greater than that shown in Table 4 .

\section{Timing of Future Fertility Preferences}

Following convention established more than two decades ago, the DHS's 2012-revised algorithm uses two years as the threshold for birth postponement that requires contraception. That is, women who want their next birth to occur two or more years in the future are regarded as needing contraception, whereas women who want their next birth to occur within two years are assumed not to have a reason to practice contraception. One could argue that this threshold is too long, because some women who want to delay a birth for two years but do not practice contraception will likely become pregnant sooner than they desire, and hence this assumption results in an underestimation of unmet need for spacing. This

\footnotetext{
${ }^{11}$ In eight countries, unmet need prevalence using the Casterline-El-Zeini estimator is slightly lower than the prevalence when the retrospective child-wantedness reports are used. This reflects that sometimes the percentage of recent unwanted births reported retrospectively is higher than the Casterline-El-Zeini estimate. With the exception of Ghana, in all of these countries the estimated percentage of recent unwanted births according to either estimator is less than 4 percent. Thus, the absolute difference between the two estimates of percentage of unwanted births is very small.
} 
reasoning suggests that the threshold should be shorter-for example, one year rather than two.

The impact of shortening the threshold for need for spacing to one year is examined in Table 5. As anticipated, this has the effect of increasing unmet need, but not by as great an amount as might have been expected. Average unmet need across 60 countries increases by 1.6 percentage points. The impact is greatest (2.4 percentage points) in West and Central Africa, where unmet need for birth spacing is a dominant feature of the reproductive regimes and most unmet need is for spacing rather than limiting (Bradley et al. 2012).

Duration of Postpartum Amenorrhea-The DHS algorithm assumes that women who are postpartum amenorrheic have no need for contraception to protect against another pregnancy. For the purposes of estimating unmet need, they are classified according to the wantedness of the most recent birth. This rule applies to women up to 24 months postpartum, after which the algorithm classifies nonusers according to their preferences for another child. The 24-month threshold far exceeds the usual guidelines in family planning service provision. Standard clinical advice is for women to begin practicing contraception by 6 months postpartum if they are sexually active and wish to avoid becoming pregnant anytime soon (WHO, JHU/CCP, and USAID 2011).

Accordingly, in Table 6 we examine the impact on estimates of unmet need if the assumed period of protection while women are postpartum amenorrheic is lowered from 24 to 6 months. Note that this change in the algorithm does not automatically lead to higher estimates of unmet need. Changing this threshold means that the need of some womenamenorrheic women 7-24 months postpartum-will be assessed on the basis of prospective preferences rather than retrospective child wantedness. Assessment based on prospective preferences will not necessarily show more contraceptive need than assessment based on retrospective child wantedness, although ordinarily this will be the case because the women are at higher parity. In fact, the impact of this revision of the algorithm on estimates of unmet need can be quite substantial and varies widely across regions: a 3.4 percentage point increase on average, ranging from 0.7 percentage points in the North Africa/West Asian/ Europe surveys to a 6.4 percentage point, or 20 percent, increase in West and Central African surveys. In half of the countries analyzed, the impact is less than 2 percentage points, and in another 18 countries it equals or exceeds 5 percentage points. Two clear conclusions can be drawn. First, estimation of unmet need is highly sensitive to the designated length of time during which postpartum amenorrhea is a trustworthy signal of inability to conceive. Second, the 24-month value employed in the DHS's 2012-revised algorithm is far higher than typical family planning guidelines and therefore leads to estimates of unmet need that are substantially lower than sound family planning practice would suggest.

\section{SUMMARY AND CONCLUSION}

Whereas the concept of unmet need for family planning is relatively simple, the task of estimating its prevalence in a population has proved challenging. The strategies for achieving this end that have developed over the years have become increasingly complex, 
except for the modest simplification achieved in the 2012 revision of the DHS's unmet need algorithm. Of more consequence than the complexity is the need to make assumptions whose validity is not readily verified. These include assumptions regarding frequency of sexual activity that places women at risk of conception, women's biological capacity to conceive, the validity of women's retrospective reports of whether recent births were desired at the time of conception, and the length of time after delivery that postpartum amenorrhea can be regarded as a trustworthy indicator that a woman cannot yet conceive again. The sensitivity tests in this article demonstrate that unmet need estimates are affected by these assumptions, in some instances to a marked extent. Our point is not that the current set of assumptions is invalid, but that plausible arguments exist for alternative assumptions that, as we have shown, would lead to meaningful different estimates of the prevalence of unmet need (usually a higher estimate).

More specifically, we find that unmet need estimates are: (1) highly sensitive to the choice of duration of postpartum amenorrhea during which women are assumed to be unable to conceive, for example 24 months (as in the current algorithm) versus 6 months (standard clinical advice), especially in settings where a substantial proportion of the population is post-partum amenorrheic (e.g., in many sub-Saharan African countries); (2) moderately sensitive to the criteria for identifying infecund women, assumptions regarding exposure to the risk of pregnancy among married women (though the impact is large in a few countries), and to the threshold chosen for the need for birth spacing (e.g., wishing to postpone the next birth for one year versus two); (3) hardly sensitive to likely downward biases in the retrospective reporting of unwanted births and in the reporting of sexual activity among unmarried women.

Many of these assumptions concern goals for contraceptive coverage in a population. A curious gap in the literature on unmet need is the lack of serious discussion of contraceptive goals. At first this matter was resolved with the concurrence on eliminating unmet need as the ultimate goal: the goal is contraception by all women who wish to avoid pregnancy. In fact, though, this leaves much unresolved. First, there is the question of the acceptability of induced abortion as an alternative means of birth control. Is the aim to avoid unintended pregnancies or unintended births? If the latter, then both contraception and safe induced abortion can serve as birth control, and contraceptive coverage can be incomplete if effectively backstopped by induced abortion. This question of whether the aim is to avoid unintended pregnancies or unintended births has some bearing on the strictness of the criteria employed to identify women who are sexually active and women who are fecund.

Consider the important case of unmarried women. Women who have not had sex during the past month are classified as sexually inactive under the DHS algorithm and therefore not in need of contraception. Some of these women undoubtedly have sex occasionally, however, and, because they do not want to become pregnant, would seem to be in need of some form of contraceptive protection. Similarly, women who want to postpone their next birth for less than two years are assumed to have no need for contraception for spacing purposes, although clearly they are at risk of having a child sooner than desired if they are sexually active and not practicing contraception. Likewise, women who are postpartum amenorrheic 12 months 
after the birth of a child are assumed to have no need for contraceptive protection, contrary to standard clinical advice.

These assumptions raise a large question: What is desirable contraceptive coverage in the "perfect contracepting" society? And a related question is: What principles should guide the answer to this large question? These are questions that warrant broad and thoughtful engagement. If the aim is the prevention of unintended pregnancies, then the contraceptive goal would be higher than indicated by the current DHS algorithm. Some unnecessary contraceptive coverage (although this cannot be known) seems defensible as an insurance policy, especially given the beneficial health effects, on balance, of many methods of contraception (Cleland et al. 2012).

The deceptive simplicity of the concept of unmet need has led to misunderstanding concerning what the multidecade effort to estimate unmet need from survey data has striven to accomplish. The fundamental objective of unmet need estimators is a population-level assessment of the discrepancy between prevailing fertility preferences and prevailing contraceptive use: how much additional contraceptive use would follow from full implementation of existing fertility preferences? Two important points must be recognized. First, classification of individual women in terms of contraceptive need at the time of the survey has not been an objective, except to the extent that it facilitates the fundamental objective just articulated. As it happens, in its effort to achieve the aim of valid populationlevel estimates of current levels of unmet need, the current DHS unmet need algorithm fails as a basis for classification of women's current need (e.g., some pregnant women are classified as having unmet need, and some women who are plausibly fecund and want to avoid pregnancy are classified as having no need).

Second, the widely used survey estimates of unmet need are not based on direct and explicit expressions by nonusers of a desire to practice contraception. Interpreting these estimates as the proportion of women "who want to use contraception but do not have access to contraceptive supplies and services" is convenient, but this reveals a misunderstanding of unmet need. As described above, the unmet need algorithm makes use of no survey items regarding a woman's interest in practicing contraception or her intention to do so. Existing survey-based estimates identify segments of the population in which a greater or lesser gap exists between reproductive preferences and contraceptive use. These estimates, however, neither reveal which segments of the population have higher or lower desires to practice contraception nor take account of the mix of incentives and barriers to contraceptive practice that nonusers confront.

These two important points reinforce the main goal of this article-namely, the identification of the strengths and limitations of the widely used approach to estimating unmet need drawn from demographic survey (e.g., DHS) data. The goal of the 2012 revision of the unmet need algorithm was to allow unmet need to be calculated in a consistent way across multiple surveys, providing estimates that are comparable across countries and over time. Our criticisms and the results from our sensitivity tests should not obscure the overall success of this approach in generating population-based national estimates. Yet along with recognition of this important achievement should come mindfulness that taking into account 
women's stated reasons for nonuse (such as no or infrequent sex) and clinical advice regarding the duration of postpartum infecundity can shift national-level estimates of unmet need.

Of greater concern are the deficiencies in this approach when used for purposes other than population-level estimates. Most notably, this approach cannot provide a precise measure of individual women's needs for family planning at the time of the survey interview. From this it follows that the standard approach can break down when used for certain highly focused purposes, such as assessing current and future contraceptive needs among women who are pregnant or postpartum amenorrheic. Users must therefore be cognizant of how unmet need is measured and consider whether alternative measures should be used that would better serve their needs.

For consistent, comparable, national-level estimates of the hypothetical level by which contraceptive prevalence would need to increase in order to achieve women's fertility preferences, the DHS algorithm is unlikely to be displaced in the foreseeable future. This should not, however, foreclose creative development of tools for assessing contraceptive need from alternative perspectives and for different purposes. The alternative assumptions used in our analysis can be used as a starting point for such approaches. The family planning field will not be well served by monolithic commitment to an algorithm designed for the essential, yet limited, task of generating population-level estimates of the prevalence of unmet need.

\section{ACKNOWLEDGMENTS}

We gratefully acknowledge helpful comments and feedback from Trevor Croft and assistance from Sarah Layton. This research was supported in part by grant T32-HD007275 from the Eunice Kennedy Shriver National Institute of Child Health and Human Development (NICHD) awarded to the University of California at Berkeley and from NICHD grant R24-058484 awarded to the Institute for Population Research at the Ohio State University.

\section{REFERENCES}

Anderson, John E.; Morris, Leo. Fertility differences and the need for family planning services in five Latin American countries. International Family Planning Perspectives. 1981; 7(1):16-21.

Berelson, Bernard. Family-planning programs and population control. In: Berelson, Bernard, editor. Family-Planning Programs: An International Survey. Basic Books; New York: 1969. p. 291-303.

Bogue, Donald J. Population perspectives: Some views from a sociologist. Population Dynamics Quarterly. 1974; 2(2):2-20. [PubMed: 12229429]

Bongaarts, John; Cleland, John; Townshend, John; Bertrand, Jane; Gupta, Monica das. Family Planning Programs for the 21st Century: Rationale and Design. Population Council; New York: 2012.

Bradley, Sarah E.K.; Croft, Trevor N.; Fishel, Joy D.; Westoff, Charles F. Revising Unmet Need for Family Planning. ICF International; Calverton, MD: 2012. DHS Analytical Studies No. 25

Casterline, John B.; El-Zeini, Laila O. The estimation of unwanted fertility. Demography. 2007; 44(4): 729-745. [PubMed: 18232208]

Casterline, John B.; Odden, Colin. Measurement of infecundity for family planning research. Institute for Population Research, Ohio State University; 2014.

Casterline, John B.; Sinding, Steven W. Unmet need for family planning in developing countries and implications for population policy. Population and Development Review. 2000; 26(4):691-723. 
Cleland, John; Bernstein, Stan; Ezeh, Alex; Faundes, Anibal; Glasier, Anna; Innis, Jolene. Family planning: The unfinished agenda. The Lancet. 2006; 368(9549):10-27.

Cleland, John; Shah, Iqbal. Contraceptive revolution: Focused efforts are still needed. The Lancet. 2013; 383(9878):1604-1606.

Connelly, Matthew. Population control in India: Prologue to the Emergency Period. Population and Development Review. 2006; 32(4):629-667.

Darroch, Jacqueline E.; Singh, Susheela. Adding it up-Costs and benefits of contraceptive services: Estimates for 2012. Guttmacher Institute and United Nations Population Fund (UNFPA); New York: 2012.

Darroch, Jacqueline E.; Singh, Susheela. Trends in contraceptive need and use in developing countries in 2003, 2008, and 2012: An analysis of national surveys. The Lancet. 2013; 381(9879):17561762.

Davis, Kingsley. Population policy: Will current programs succeed? Science. 1967; 158(3802):730739. [PubMed: 6069101]

El-Zeini, Laila O. Categorizing the need for family planning: A story of evolution.. Paper presented at the IUSSP Seminar on Social Categories in Population Studies; Cairo. 15-18 September; 1999.

Freedman, Ronald; Coombs, Lolagene C. Cross-cultural Comparisons: Data on Two Factors in Fertility Behavior. Population Council; New York: 1974.

Freedman, Ronald; Coombs, Lolagene C.; Chang, Ming Chen. Trends in family size preferences and practice of family planning: Taiwan, 1965-1970. Studies in Family Planning. 1972; 3(12):281296.

Hauser, Philip N. Population: More than family planning. Journal of Medical Education. 1969; 44(11, Part 2):20-29. [PubMed: 5390732]

Kelley, Allen C. Economic consequences of population change in the Third World. Journal of Economic Literature. 1988; 26(4):1685-1728.

Lightbourne, Robert E. Individual preferences and fertility behaviour. In: Cleland, J.; Hobcraft, J., editors. Reproductive Change in Developing Countries: Insights from the World Fertility Survey. Oxford University Press; 1985. p. 165-198.

Mauldin, W. Parker Fertility studies: Knowledge, attitude, and practice. Studies in Family Planning. 1965; 1(7):1-10.

McCauley, P.; Robey, Bryant; Blanc, Ann; Geller, J. Opportunities for Women through Reproductive Choice. Johns Hopkins University; Baltimore, MD: 1994. Population Reports, Series M, No. 12

McIntosh, C. Alison; Finkle, Jason L. The Cairo Conference on Population and Development: A new paradigm? Population and Development Review. 1995; 21(2):223-260.

MEASURE DHS. [5 March 2013] Unmet Need for Family Planning. 2013. http://measuredhs.com/ Topics/Unmet-Need.cfm.

Morris, Leo; Lewis, Gary; Powell, Dorian L.; Anderson, John; Way, Ann. Contraceptive Prevalence Surveys: A New Source of Family Planning Data. Johns Hopkins University; Baltimore, MD: 1981. Population Reports, Series M, No. 5

Nortman, Dorothy L. Measuring the unmet need for contraception to space and limit births. International Family Planning Perspectives. 1982; 8(4):125-134.

Nortman, Dorothy L.; Lewis, Gary L. A time model to measure contraceptive demand. In: Ross, JA.; McNamara, R., editors. Survey Analysis for the Guidance of Family Planning Programs. Ordina Editions; Liege, Belgium: 1984. p. 37-73.

Peterson, Herbert B.; Darmstadt, Gary L.; Bongaarts, John. Meeting the unmet need for family planning: Now is the time. The Lancet. 2013; 381(9879):1696-1699.

Pritchett Lant H. Desired fertility and the impact of population policies. Population and Development Review. 1994; 20(1):1-55.

Robey, Bryant; Ross, John A.; Bhushan, Indu. Meeting Unmet Need: New Strategies. Johns Hopkins School of Public Health, Population Information Program; Baltimore, MD: 1996. Population Reports, Series J, No. 43

Sen, Gita; Germain, Adrienne; Chen, Lincoln C. Population Policies Reconsidered: Health, Empowerment, and Rights. Harvard University Press; Cambridge, MA: 1994. 
Sinding, Steven W.; Ross, John A.; Rosenfield, Allan G. Seeking common ground: Unmet need and demographic goals. International Family Planning Perspectives. 1994; 20(1):23-27. 32.

Westoff, Charles F. The unmet need for birth control in five Asian countries. Family Planning Perspectives. 1978; 10(3):173-81. [PubMed: 658326]

Westoff, Charles F. The potential demand for family planning: A new measure of unmet need and estimates for five Latin American countries. International Family Planning Perspectives. 1988; 14(2):45-53.

Westoff, Charles F. Unmet Need at the End of the Century. Macro International; Calverton, MD: 2001. DHS Comparative Reports No. 1

Westoff, Charles F. New Estimates of Unmet Need and the Demand for Family Planning. Macro International; Calverton, MD: 2006. DHS Comparative Reports No. 14

Westoff, Charles F.; Bankole, Akinrinola. Unmet Need: 1990-1994. Macro International; Calverton, MD: 1995. DHS Comparative Studies No. 16

Westoff, Charles F.; Bankole, Akinrinola. The potential demographic significance of unmet need. International Family Planning Perspectives. 1996; 22(1):16-20.

Westoff, Charles F.; Ochoa, Luis H. Unmet Need and the Demand for Family Planning. Institute for Resource Development; Columbia, MD: 1991. DHS Comparative Studies No. 5

Westoff, Charles F.; Pebley, Ann R. Alternative measures of unmet need for family planning in developing countries. International Family Planning Perspectives. 1981; 7(4):126-136.

World Health Organization (WHO), Johns Hopkins University Center for Communication Programs (JHU/CCP), and the United States Agency for International Development (USAID). [20 January 2013] Family planning: A global handbook for providers. 2011. http://www.fphandbook.org. 
TABLE 1

Percentage of married women aged 15-49 having unmet need, by region and country, according to the 2012revised algorithm and a definition taking into account sexual inactivity, 60 countries, 2001-13

\begin{tabular}{|c|c|c|c|c|}
\hline Region/country and year of DHS survey & $\begin{array}{l}\text { Percent having } \\
\text { unmet need, 2012- } \\
\text { revised algorithm }\end{array}$ & $\begin{array}{r}\text { Percent having } \\
\text { unmet need, treating } \\
\text { women with no/ } \\
\text { infrequent sex as } \\
\text { having no unmet } \\
\text { need }\end{array}$ & $\begin{array}{r}\text { Differences due to } \\
\text { treating women } \\
\text { having no/infrequent } \\
\text { sex as having no } \\
\text { unmet need }\end{array}$ & $\begin{array}{r}\text { Currently married } \\
\text { women (weighted } \\
\mathrm{N})\end{array}$ \\
\hline East and Southern Africa & 24.3 & 21.5 & -2.8 & \\
\hline Burundi 2010 & 32.4 & 30.5 & -1.9 & $(5,421)$ \\
\hline Ethiopia 2011 & 26.3 & 24.7 & -1.6 & $(10,287)$ \\
\hline Kenya 2008-09 & 25.6 & 22.9 & -2.7 & $(4,928)$ \\
\hline Lesotho 2009 & 23.3 & 18.5 & -4.8 & $(4,049)$ \\
\hline Madagascar 2008-09 & 19.0 & 17.1 & -1.9 & $(12,039)$ \\
\hline Malawi 2010 & 26.2 & 22.3 & -3.9 & $(15,528)$ \\
\hline Mozambique 2011 & 23.9 & 20.2 & -3.7 & $(9,332)$ \\
\hline Namibia 2006-07 & 20.7 & 19.6 & -1.1 & $(3,451)$ \\
\hline Rwanda 2010 & 20.8 & 18.1 & -2.7 & $(6,897)$ \\
\hline Swaziland 2006-07 & 24.7 & 23.1 & -1.6 & $(2,062)$ \\
\hline Tanzania 2010 & 22.3 & 19.3 & -3.0 & $(6,412)$ \\
\hline Uganda 2011 & 34.3 & 30.7 & -3.6 & $(5,418)$ \\
\hline Zambia 2007 & 26.6 & 22.7 & -3.9 & $(4,402)$ \\
\hline Zimbabwe 2010-11 & 14.6 & 11.2 & -3.4 & $(5,703)$ \\
\hline West and Central Africa & 26.8 & 23.5 & -3.3 & \\
\hline Benin 2011-12 & 32.6 & 29.5 & -3.1 & $(11,680)$ \\
\hline Burkina Faso 2010 & 24.5 & 19.6 & -4.9 & $(13,563)$ \\
\hline Cameroon 2011 & 23.5 & 18.5 & -5.0 & $(9,792)$ \\
\hline Chad 2004 & 20.6 & 19.2 & -1.4 & $(4,663)$ \\
\hline Congo (Brazzaville) 2011-12 & 18.4 & 16.8 & -1.6 & $(6,289)$ \\
\hline Congo (Democratic Republic) 2007 & 26.9 & 22.6 & -4.3 & $(6,622)$ \\
\hline Cote d'Ivoire 2011-12 & 27.1 & 23.9 & -3.2 & $(6,309)$ \\
\hline Gabon 2012 & 26.5 & 23.6 & -2.9 & $(4,475)$ \\
\hline Ghana 2008 & 35.7 & 30.0 & -5.7 & $(2,876)$ \\
\hline Guinea 2012 & 23.7 & 20.8 & -2.9 & $(6,726)$ \\
\hline Liberia 2007 & 35.7 & 32.1 & -3.6 & $(4,540)$ \\
\hline Mali 2006 & 27.6 & 26.2 & -1.4 & $(12,365)$ \\
\hline Niger 2012 & 16.0 & 13.6 & -2.4 & $(9,881)$ \\
\hline Nigeria 2008 & 20.2 & 18.4 & -1.8 & $(23,578)$ \\
\hline Sao Tome and Principe 2008-09 & 37.6 & 33.0 & -4.6 & $(1,718)$ \\
\hline Senegal 2010-11 & 30.1 & 25.9 & -4.2 & $(10,347)$ \\
\hline Sierra Leone 2008 & 28.4 & 25.6 & -2.8 & $(5,525)$ \\
\hline North Africa/West Asia/Europe & 13.5 & 10.2 & -3.3 & \\
\hline Albania 2008-09 & 12.9 & 9.8 & -3.1 & $(5,001)$ \\
\hline
\end{tabular}




\begin{tabular}{|c|c|c|c|c|}
\hline Region/country and year of DHS survey & $\begin{array}{l}\text { Percent having } \\
\text { unmet need, 2012- } \\
\text { revised algorithm }\end{array}$ & $\begin{array}{r}\text { Percent having } \\
\text { unmet need, treating } \\
\text { women with no/ } \\
\text { infrequent sex as } \\
\text { having no unmet } \\
\text { need }\end{array}$ & $\begin{array}{r}\text { Differences due to } \\
\text { treating women } \\
\text { having no/infrequent } \\
\text { sex as having no } \\
\text { unmet need }\end{array}$ & $\begin{array}{r}\text { Currently married } \\
\text { women (weighted } \\
\mathrm{N})\end{array}$ \\
\hline Armenia 2010 & 13.5 & 9.0 & -4.5 & $(3,626)$ \\
\hline Azerbaijan 2006 & 15.4 & 11.6 & -3.8 & $(5,269)$ \\
\hline Egypt 2008 & 11.6 & 8.1 & -3.5 & $(15,396)$ \\
\hline Jordan 2012 & 11.7 & 9.2 & -2.5 & $(10,801)$ \\
\hline Kyrgyz Republic 2012 & 18.0 & 15.9 & -2.1 & $(5,256)$ \\
\hline Moldova 2005 & 11.4 & 7.7 & -3.7 & $(4,937)$ \\
\hline Morocco 2003-04 & 11.9 & 7.4 & -4.5 & $(8,782)$ \\
\hline Tajikistan 2012 & 22.9 & 17.9 & -5.0 & $(6,504)$ \\
\hline Turkey 2003 & 9.5 & 8.9 & -0.6 & $(3,902)$ \\
\hline Ukraine 2007 & 10.1 & 7.2 & -2.9 & $(4,116)$ \\
\hline Asia and Pacific & 19.2 & 14.6 & -4.6 & \\
\hline Bangladesh 2011 & 13.5 & 7.3 & -6.2 & $(16,635)$ \\
\hline Cambodia 2010 & 16.9 & 11.8 & -5.1 & $(11,626)$ \\
\hline India 2005-06 & 13.9 & 10.8 & -3.1 & $(93,089)$ \\
\hline Indonesia 2012 & 11.4 & 9.5 & -1.9 & $(33,465)$ \\
\hline Maldives 2009 & 28.6 & 28.2 & -0.4 & $(6,500)$ \\
\hline Nepal 2011 & 27.5 & 10.0 & -17.5 & $(9,608)$ \\
\hline Pakistan 2012-13 & 20.1 & 15.0 & -5.1 & $(12,937)$ \\
\hline Philippines 2008 & 22.0 & 16.7 & -5.3 & $(8,418)$ \\
\hline Timor-Leste 2009-10 & 31.5 & 31.0 & -0.5 & $(7,906)$ \\
\hline Vietnam 2002 & 6.6 & 6.0 & -0.6 & $(5,338)$ \\
\hline Latin America and Caribbean & 17.2 & 13.8 & -3.4 & \\
\hline Bolivia 2008 & 20.1 & 14.3 & -5.8 & $(10,162)$ \\
\hline Colombia 2010 & 8.0 & 6.6 & -1.4 & $(26,247)$ \\
\hline Dominican Republic 2007 & 11.1 & 9.4 & -1.7 & $(15,417)$ \\
\hline Guyana 2009 & 28.5 & 24.4 & -4.1 & $(2,920)$ \\
\hline Haiti 2012 & 35.3 & 30.9 & -4.4 & $(7,808)$ \\
\hline Honduras 2011-12 & 10.7 & 7.0 & -3.7 & $(12,847)$ \\
\hline Nicaragua 2001 & 14.6 & 12.0 & -2.6 & $(7,424)$ \\
\hline Peru 2012 & 9.3 & 6.1 & -3.2 & $(13,624)$ \\
\hline Unweighted averages & 21.2 & 17.8 & -3.4 & \\
\hline
\end{tabular}

NOTE: Regional estimates are unweighted averages of the country-specific estimates. 
TABLE 2

Percentage of sexually active women aged 15-49 having unmet need, by region and country, according to scope of definition of "sexually active" women, 43 countries, 2001-12

\begin{tabular}{|c|c|c|c|c|c|}
\hline \multirow[b]{2}{*}{$\begin{array}{l}\text { Region/country and year of DHS } \\
\text { survey }\end{array}$} & \multicolumn{2}{|c|}{ Unmarried sexually active women } & \multicolumn{3}{|c|}{ All sexually active women } \\
\hline & $\begin{array}{r}\text { Percentage } \\
\text { having unmet } \\
\text { need }\end{array}$ & $\begin{array}{r}\text { Weighted } \\
\text { number of } \\
\text { women }\end{array}$ & $\begin{array}{r}\text { Percent } \\
\text { having unmet } \\
\text { need }\end{array}$ & $\begin{array}{r}\text { Percent } \\
\text { having unmet } \\
\text { need, weight } \\
\text { inflated }\end{array}$ & $\begin{array}{r}\text { Difference in } \\
\text { unmet need if two } \\
\text { times as many } \\
\text { sexually active } \\
\text { unmarried women } \\
\text { were in the } \\
\text { population }\end{array}$ \\
\hline East and Southern Africa & 31.9 & & 24.2 & 24.7 & 0.5 \\
\hline Burundi 2010 & 42.5 & (89) & 32.6 & 32.7 & 0.1 \\
\hline Ethiopia 2011 & 24.4 & (197) & 26.3 & 26.2 & -0.1 \\
\hline Kenya 2008-09 & 35.3 & (318) & 26.2 & 26.7 & 0.5 \\
\hline Lesotho 2009 & 32.0 & (466) & 24.2 & 24.9 & 0.7 \\
\hline Madagascar 2008-09 & 36.8 & (815) & 20.1 & 21.1 & 1.0 \\
\hline Malawi 2010 & 38.3 & $(523)$ & 26.6 & 27.0 & 0.4 \\
\hline Mozambique 2011 & 40.6 & $(1,150)$ & 25.7 & 27.2 & 1.5 \\
\hline Namibia 2006-07 & 15.7 & $(1,343)$ & 19.3 & 18.5 & -0.8 \\
\hline Rwanda 2010 & 39.3 & (246) & 21.4 & 22.0 & 0.6 \\
\hline Swaziland 2006-07 & 28.5 & (573) & 25.6 & 26.1 & 0.5 \\
\hline Tanzania 2010 & 31.0 & (743) & 23.2 & 24.0 & 0.8 \\
\hline Uganda 2011 & 29.7 & (321) & 34.0 & 33.8 & -0.2 \\
\hline Zambia 2007 & 38.4 & $(320)$ & 27.4 & 28.1 & 0.7 \\
\hline Zimbabwe 2010-11 & 25.3 & (266) & 15.0 & 15.5 & 0.5 \\
\hline West and Central Africa & 38.2 & & 28.2 & 28.8 & 0.6 \\
\hline Benin 2011-12 & 45.3 & (918) & 33.5 & 34.3 & 0.8 \\
\hline Burkina Faso 2010 & 31.8 & (348) & 24.7 & 24.9 & 0.2 \\
\hline Cameroon 2011 & 24.6 & $(1,127)$ & 23.6 & 23.7 & 0.1 \\
\hline Chad 2004 & 38.6 & (70) & 20.8 & 21.1 & 0.3 \\
\hline Congo (Brazzaville) 2011-12 & 15.6 & $(1,504)$ & 17.8 & 17.5 & -0.3 \\
\hline Congo (Democratic Republic) 2007 & 35.3 & $(653)$ & 27.7 & 28.3 & 0.6 \\
\hline Cote d'Ivoire 2011-12 & 43.9 & $(1,185)$ & 29.8 & 31.7 & 1.9 \\
\hline Gabon 2012 & 28.2 & $(1,479)$ & 26.9 & 27.2 & 0.3 \\
\hline Ghana 2008 & 39.8 & $(284)$ & 36.0 & 36.3 & 0.3 \\
\hline Guinea 2012 & 41.9 & (387) & 24.7 & 25.6 & 0.9 \\
\hline Liberia 2007 & 51.6 & $(1,046)$ & 38.6 & 40.7 & 2.1 \\
\hline Mali 2006 & 41.8 & (114) & 27.7 & 27.8 & 0.1 \\
\hline Nigeria 2008 & 30.8 & $(1,607)$ & 20.9 & 21.5 & 0.6 \\
\hline Sao Tome and Principe 2008-09 & 38.3 & (146) & 37.7 & 37.7 & 0.0 \\
\hline Senegal 2010-11 & 58.6 & (138) & 30.5 & 30.8 & 0.3 \\
\hline Sierra Leone 2008 & 45.3 & $(551)$ & 29.9 & 31.2 & 1.3 \\
\hline North Africa/West Asia/Europe & 23.7 & & 13.3 & 13.6 & 0.3 \\
\hline Albania 2008-09 & 19.6 & (154) & 13.1 & 13.3 & 0.2 \\
\hline
\end{tabular}




\begin{tabular}{|c|c|c|c|c|c|}
\hline \multirow[b]{2}{*}{$\begin{array}{l}\text { Region/country and year of DHS } \\
\text { survey }\end{array}$} & \multicolumn{2}{|c|}{ Unmarried sexually active women } & \multicolumn{3}{|c|}{ All sexually active women } \\
\hline & $\begin{array}{r}\text { Percentage } \\
\text { having unmet } \\
\text { need }\end{array}$ & $\begin{array}{r}\text { Weighted } \\
\text { number of } \\
\text { women }\end{array}$ & $\begin{array}{r}\text { Percent } \\
\text { having unmet } \\
\text { need }\end{array}$ & $\begin{array}{r}\text { Percent } \\
\text { having unmet } \\
\text { need, weight } \\
\text { inflated }\end{array}$ & $\begin{array}{l}\text { Difference in } \\
\text { unmet need if two } \\
\text { times as many } \\
\text { sexually active } \\
\text { unmarried women } \\
\text { were in the } \\
\text { population }\end{array}$ \\
\hline Kyrgyz Republic 2012 & 45.2 & $(100)$ & 18.5 & 19.0 & 0.5 \\
\hline Moldova 2005 & 24.2 & $(305)$ & 12.1 & 12.8 & 0.7 \\
\hline Ukraine 2007 & 5.7 & $(637)$ & 9.5 & 9.1 & -0.4 \\
\hline Asia and Pacific & 20.5 & & 17.6 & 18.0 & 0.3 \\
\hline Philippines 2008 & 42.5 & (115) & 22.3 & 22.6 & 0.3 \\
\hline Latin America and Caribbean & 20.5 & & 17.6 & 18.0 & 0.3 \\
\hline Bolivia 2008 & 16.2 & $(618)$ & 19.9 & 19.7 & -0.2 \\
\hline Colombia 2010 & 11.2 & $(6,335)$ & 8.6 & 9.1 & 0.5 \\
\hline Dominican Republic 2007 & 22.5 & $(2,171)$ & 12.6 & 13.6 & 1.0 \\
\hline Guyana 2009 & 25.8 & $(408)$ & 28.1 & 27.9 & -0.2 \\
\hline Haiti 2012 & 52.1 & (973) & 37.2 & 38.7 & 1.5 \\
\hline Honduras 2011-12 & 11.9 & $(1,010)$ & 10.8 & 10.9 & 0.1 \\
\hline Nicaragua 2001 & 18.4 & $(402)$ & 14.8 & 15.0 & 0.2 \\
\hline Peru 2012 & 6.2 & $(1,730)$ & 9.0 & 8.7 & -0.3 \\
\hline Unweighted averages & 31.9 & & 23.6 & 24.1 & 0.5 \\
\hline
\end{tabular}

NOTES: For unmarried women, "sexually active" is defined as reporting sexual intercourse in the 30 days prior to interview. In this analysis, all married women are assumed to be sexually active. Thus "all sexually active women" refers to women who are married or have had sex in the past 30 days. Regional estimates are unweighted averages of the country-specific estimates. Excludes ever-married surveys, and India 2005-06 and Morocco 2003-04 were excluded because never-married women were not asked all questions required to calculate unmet need. Armenia 2010, Azerbaijan 2006, Cambodia 2006, Indonesia 2012, Nepal 2011, Niger 2012, and Timor-Leste 2009-10 were excluded because they contained fewer than 50 unmarried women reporting sexual intercourse in the preceding 30 days. Because this leaves only one survey from Asia and the Pacific, estimates for this region are not presented. 


\section{TABLE 3}

Percentage of married women aged 15-49 with unmet need, by region and country, according to exclusion of infecundity condition, 60 countries, 2001-13

\begin{tabular}{|c|c|c|c|c|}
\hline Region/country and year of DHS survey & $\begin{array}{r}\text { Percent having } \\
\text { unmet need, 2012- } \\
\text { revised algorithm }\end{array}$ & $\begin{array}{r}\text { Percent having } \\
\text { unmet need, } \\
\text { excluding infecundity } \\
\text { condition }\end{array}$ & $\begin{array}{r}\text { Differences in umet } \\
\text { need resulting from } \\
\text { removing infecundity } \\
\text { condition }\end{array}$ & $\begin{array}{r}\text { Currently married } \\
\text { women (weighted } \\
\mathrm{N} \text { ) }\end{array}$ \\
\hline East and Southern Africa & 24.3 & 27.2 & 2.9 & \\
\hline Burundi 2010 & 32.4 & 35.8 & 3.4 & $(5,421)$ \\
\hline Ethiopia 2011 & 26.3 & 29.5 & 3.2 & $(10,287)$ \\
\hline Kenya 2008-09 & 25.6 & 27.9 & 2.3 & $(4,928)$ \\
\hline Lesotho 2009 & 23.3 & 28.9 & 5.6 & $(4,049)$ \\
\hline Madagascar 2008-09 & 19.0 & 22.2 & 3.2 & $(12,039)$ \\
\hline Malawi 2010 & 26.2 & 28.0 & 1.8 & $(15,528)$ \\
\hline Mozambique 2011 & 23.9 & 28.5 & 4.6 & $(9,332)$ \\
\hline Namibia 2006-07 & 20.7 & 23.1 & 2.4 & $(3,451)$ \\
\hline Rwanda 2010 & 20.8 & 24.2 & 3.4 & $(6,897)$ \\
\hline Swaziland 2006-07 & 24.7 & 26.4 & 1.7 & $(2,062)$ \\
\hline Tanzania 2010 & 22.3 & 25.3 & 3.0 & $(6,412)$ \\
\hline Uganda 2011 & 34.3 & 36.6 & 2.3 & $(5,418)$ \\
\hline Zambia 2007 & 26.6 & 28.5 & 1.9 & $(4,402)$ \\
\hline Zimbabwe 2010-11 & 14.6 & 16.2 & 1.6 & $(5,703)$ \\
\hline West and Central Africa & 26.8 & 31.3 & 4.5 & \\
\hline Benin 2011-12 & 32.6 & 39.1 & 6.5 & $(11,680)$ \\
\hline Burkina Faso 2010 & 24.5 & 29.2 & 4.7 & $(13,563)$ \\
\hline Cameroon 2011 & 23.5 & 26.7 & 3.2 & $(9,792)$ \\
\hline Chad 2004 & 20.6 & 23.2 & 2.6 & $(4,663)$ \\
\hline Congo (Brazzaville) 2011-12 & 18.4 & 20.0 & 1.6 & $(6,289)$ \\
\hline Congo (Democratic Republic) 2007 & 26.9 & 29.1 & 2.2 & $(6,622)$ \\
\hline Cote d'Ivoire 2011-12 & 27.1 & 31.5 & 4.4 & $(6,309)$ \\
\hline Gabon 2012 & 26.5 & 32.4 & 5.9 & $(4,475)$ \\
\hline Ghana 2008 & 35.7 & 39.7 & 4.0 & $(2,876)$ \\
\hline Guinea 2012 & 23.7 & 29.7 & 6.0 & $(6,726)$ \\
\hline Liberia 2007 & 35.7 & 43.7 & 8.0 & $(4,540)$ \\
\hline Mali 2006 & 27.6 & 31.8 & 4.2 & $(12,365)$ \\
\hline Niger 2012 & 16.0 & 18.1 & 2.1 & $(9,881)$ \\
\hline Nigeria 2008 & 20.2 & 25.6 & 5.4 & $(23,578)$ \\
\hline Sao Tome and Principe 2008-09 & 37.6 & 42.2 & 4.6 & $(1,718)$ \\
\hline Senegal 2010-11 & 30.1 & 34.4 & 4.3 & $(10,347)$ \\
\hline Sierra Leone 2008 & 28.4 & 35.2 & 6.8 & $(5,525)$ \\
\hline North Africa/West Asia/Europe & 13.5 & 17.2 & 3.7 & \\
\hline Albania 2008-09 & 12.9 & 16.0 & 3.1 & $(5,001)$ \\
\hline Armenia 2010 & 13.5 & 20.7 & 7.2 & $(3,626)$ \\
\hline
\end{tabular}




\begin{tabular}{|c|c|c|c|c|}
\hline Region/country and year of DHS survey & $\begin{array}{l}\text { Percent having } \\
\text { unmet need, 2012- } \\
\text { revised algorithm }\end{array}$ & $\begin{array}{r}\text { Percent having } \\
\text { unmet need, } \\
\text { excluding infecundity } \\
\text { condition }\end{array}$ & $\begin{array}{r}\text { Differences in umet } \\
\text { need resulting from } \\
\text { removing infecundity } \\
\text { condition }\end{array}$ & $\begin{array}{r}\text { Currently married } \\
\text { women (weighted } \\
\mathrm{N})\end{array}$ \\
\hline Azerbaijan 2006 & 15.4 & 22.7 & 7.3 & $(5,269)$ \\
\hline Egypt 2008 & 11.6 & 12.7 & 1.1 & $(15,396)$ \\
\hline Jordan 2012 & 11.7 & 12.9 & 1.2 & $(10,801)$ \\
\hline Kyrgyz Republic 2012 & 18.0 & 22.9 & 4.9 & $(5,256)$ \\
\hline Moldova 2005 & 11.4 & 13.7 & 2.3 & $(4,937)$ \\
\hline Morocco 2003-04 & 11.9 & 12.6 & 0.7 & $(8,782)$ \\
\hline Tajikistan 2012 & 22.9 & 31.8 & 8.9 & $(6,504)$ \\
\hline Turkey 2003 & 9.5 & 10.4 & 0.9 & $(3,902)$ \\
\hline Ukraine 2007 & 10.1 & 12.9 & 2.8 & $(4,116)$ \\
\hline Asia and Pacific & 19.2 & 23.8 & 4.6 & \\
\hline Bangladesh 2011 & 13.5 & 15.4 & 1.9 & $(16,635)$ \\
\hline Cambodia 2010 & 16.9 & 23.5 & 6.6 & $(11,626)$ \\
\hline India 2005-06 & 13.9 & 17.6 & 3.7 & $(93,089)$ \\
\hline Indonesia 2012 & 11.4 & 13.6 & 2.2 & $(33,465)$ \\
\hline Maldives 2009 & 28.6 & 37.7 & 9.1 & $(6,500)$ \\
\hline Nepal 2011 & 27.5 & 30.6 & 3.1 & $(9,608)$ \\
\hline Pakistan 2012-13 & 20.1 & 24.4 & 4.3 & $(12,937)$ \\
\hline Philippines 2008 & 22.0 & 26.1 & 4.1 & $(8,418)$ \\
\hline Timor-Leste 2009-10 & 31.5 & 41.5 & 10.0 & $(7,906)$ \\
\hline Vietnam 2002 & 6.6 & 7.5 & 0.9 & $(5,338)$ \\
\hline Latin America and Caribbean & 17.2 & 19.6 & 2.4 & \\
\hline Bolivia 2008 & 20.1 & 22.1 & 2.0 & $(10,162)$ \\
\hline Colombia 2010 & 8.0 & 8.4 & 0.4 & $(26,247)$ \\
\hline Dominican Republic 2007 & 11.1 & 12.3 & 1.2 & $(15,417)$ \\
\hline Guyana 2009 & 28.5 & 35.7 & 7.2 & $(2,920)$ \\
\hline Haiti 2012 & 35.3 & 41.0 & 5.7 & $(7,808)$ \\
\hline Honduras 2011-12 & 10.7 & 11.3 & 0.6 & $(12,847)$ \\
\hline Nicaragua 2001 & 14.6 & 16.2 & 1.6 & $(7,424)$ \\
\hline Peru 2012 & 9.3 & 9.5 & 0.2 & $(13,624)$ \\
\hline Unweighted averages & 21.2 & 24.9 & 3.7 & \\
\hline
\end{tabular}

NOTES: Infecundity condition is defined as: allowing women who married five-plus years ago, had no children in the past five years, and never used contraception to potentially have unmet need and differences from the standard (2012-revised) algorithm. Regional estimates are unweighted averages of the country-specific estimates. 
TABLE 4

Percentage of currently married women aged 15-49 currently pregnant or postpartum amenorrheic having unmet need for limiting, by region and country, according to estimator used for determining birth wantedness, 60 countries, 2001-13

\begin{tabular}{|c|c|c|c|c|c|}
\hline $\begin{array}{l}\text { Region/country and year of DHS } \\
\text { survey }\end{array}$ & $\begin{array}{r}\text { Percentage } \\
\text { currently } \\
\text { pregnant or } \\
\text { postpartum } \\
\text { amenorrheic and } \\
\text { not practicing } \\
\text { contraception }\end{array}$ & $\begin{array}{r}\text { Percentage } \\
\text { currently } \\
\text { pregnant or } \\
\text { postpartum } \\
\text { amenorrheic } \\
\text { having unmet } \\
\text { need for limiting, } \\
\text { according to } \\
\text { retrospective } \\
\text { child wantedness }\end{array}$ & $\begin{array}{r}\text { Percentage } \\
\text { currently } \\
\text { pregnant or } \\
\text { postpartum } \\
\text { amenorrheic } \\
\text { having unmet } \\
\text { need for limiting, } \\
\text { according to } \\
\text { Casterline-El- } \\
\text { Zeini estimator }\end{array}$ & $\begin{array}{r}\text { Difference in } \\
\text { unmet need for } \\
\text { limiting } \\
\text { resulting from } \\
\text { using } \\
\text { Casterline-El- } \\
\text { Zeini estimator }\end{array}$ & $\begin{array}{r}\text { Currently } \\
\text { married } \\
\text { women } \\
\text { (weighted N) }\end{array}$ \\
\hline East and Southern Africa & 27.2 & 3.3 & 6.3 & 3.0 & \\
\hline Burundi 2010 & 43.3 & 2.9 & 8.0 & 5.1 & $(5,421)$ \\
\hline Ethiopia 2011 & 35.5 & 3.6 & 10.3 & 6.6 & $(10,287)$ \\
\hline Kenya 2008-09 & 22.7 & 3.3 & 5.2 & 1.9 & $(4,928)$ \\
\hline Lesotho 2009 & 14.7 & 1.6 & 3.3 & 1.7 & $(4,049)$ \\
\hline Madagascar 2008-09 & 24.7 & 1.2 & 5.3 & 4.1 & $(12,039)$ \\
\hline Malawi 2010 & 25.3 & 6.8 & 7.0 & 0.2 & $(15,528)$ \\
\hline Mozambique 2011 & 37.4 & 1.3 & 5.8 & 4.5 & $(9,332)$ \\
\hline Namibia 2006-07 & 14.5 & 3.1 & 4.7 & 1.6 & $(3,451)$ \\
\hline Rwanda 2010 & 25.6 & 3.8 & 8.0 & 4.2 & $(6,897)$ \\
\hline Swaziland 2006-07 & 13.7 & 4.1 & 5.1 & 1.0 & $(2,062)$ \\
\hline Tanzania 2010 & 29.4 & 1.0 & 3.5 & 2.4 & $(6,412)$ \\
\hline Uganda 2011 & 37.2 & 5.2 & 10.7 & 5.4 & $(5,418)$ \\
\hline Zambia 2007 & 30.1 & 4.2 & 4.5 & 0.3 & $(4,402)$ \\
\hline Zimbabwe 2010-11 & 17.6 & 1.4 & 3.5 & 2.1 & $(5,703)$ \\
\hline West and Central Africa & 31.3 & 1.8 & 2.8 & 1.0 & \\
\hline Benin 2011-12 & 29.6 & 2.1 & 2.1 & 0.0 & $(11,680)$ \\
\hline Burkina Faso 2010 & 35.8 & 0.5 & 2.2 & 1.6 & $(13,563)$ \\
\hline Cameroon 2011 & 32.0 & 1.9 & 2.7 & 0.8 & $(9,792)$ \\
\hline Chad 2004 & 41.4 & 0.3 & 0.9 & 0.6 & $(4,663)$ \\
\hline Congo (Brazzaville) 2011-12 & 26.8 & 1.3 & 2.3 & 1.0 & $(6,289)$ \\
\hline Congo (Democratic Republic) 2007 & 35.8 & 2.7 & 1.9 & -0.8 & $(6,622)$ \\
\hline Cote d'Ivoire 2011-12 & 30.6 & 1.3 & 2.1 & 0.8 & $(6,309)$ \\
\hline Gabon 2012 & 22.1 & 1.5 & 3.9 & 2.4 & $(4,475)$ \\
\hline Ghana 2008 & 26.7 & 3.8 & 3.3 & -0.6 & $(2,876)$ \\
\hline Guinea 2012 & 33.6 & 0.8 & 2.9 & 2.1 & $(6,726)$ \\
\hline Liberia 2007 & 29.7 & 1.3 & 3.1 & 1.8 & $(4,540)$ \\
\hline Mali 2006 & 37.1 & 1.1 & 2.6 & 1.4 & $(12,365)$ \\
\hline Niger 2012 & 41.8 & 0.3 & 0.4 & 0.1 & $(9,881)$ \\
\hline Nigeria 2008 & 36.7 & 1.2 & 0.7 & -0.6 & $(23,578)$ \\
\hline Sao Tome and Principe 2008-09 & 22.9 & 7.1 & 10.6 & 3.5 & $(1,718)$ \\
\hline Senegal 2010-11 & 31.5 & 1.3 & 2.1 & 0.8 & $(10,347)$ \\
\hline
\end{tabular}




\begin{tabular}{|c|c|c|c|c|c|}
\hline $\begin{array}{l}\text { Region/country and year of DHS } \\
\text { survey }\end{array}$ & $\begin{array}{r}\text { Percentage } \\
\text { currently } \\
\text { pregnant or } \\
\text { postpartum } \\
\text { amenorrheic and } \\
\text { not practicing } \\
\text { contraception }\end{array}$ & $\begin{array}{r}\text { Percentage } \\
\text { currently } \\
\text { pregnant or } \\
\text { postpartum } \\
\text { amenorrheic } \\
\text { having unmet } \\
\text { need for limiting, } \\
\text { according to } \\
\text { retrospective } \\
\text { child wantedness }\end{array}$ & $\begin{array}{r}\text { Percentage } \\
\text { currently } \\
\text { pregnant or } \\
\text { postpartum } \\
\text { amenorrheic } \\
\text { having unmet } \\
\text { need for limiting, } \\
\text { according to } \\
\text { Casterline-El- } \\
\text { Zeini estimator }\end{array}$ & $\begin{array}{r}\text { Difference in } \\
\text { unmet need for } \\
\text { limiting } \\
\text { resulting from } \\
\text { using } \\
\text { Casterline-El- } \\
\text { Zeini estimator }\end{array}$ & 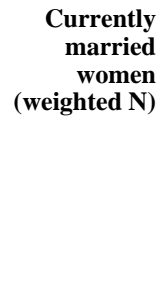 \\
\hline Sierra Leone 2008 & 30.0 & 3.1 & 3.8 & 0.7 & $(5,525)$ \\
\hline North Africa/West Asia/Europe & 12.2 & 0.9 & 1.3 & 0.5 & \\
\hline Albania 2008-09 & 4.0 & 0.1 & 0.1 & 0.0 & $(5,001)$ \\
\hline Armenia 2010 & 6.7 & 0.1 & 0.0 & -0.1 & $(3,626)$ \\
\hline Azerbaijan 2006 & 8.0 & 0.6 & 0.5 & 0.0 & $(5,269)$ \\
\hline Egypt 2008 & 13.1 & 0.9 & 2.4 & 1.5 & $(15,396)$ \\
\hline Jordan 2012 & 12.6 & 1.0 & 1.7 & 0.7 & $(10,801)$ \\
\hline Kyrgyz Republic 2012 & 19.2 & 0.2 & 0.0 & -0.2 & $(5,256)$ \\
\hline Moldova 2005 & 4.9 & 0.2 & 0.1 & -0.1 & $(4,937)$ \\
\hline Morocco 2003-04 & 9.9 & 1.3 & 2.0 & 0.7 & $(8,782)$ \\
\hline Tajikistan 2012 & 17.9 & 0.6 & 1.7 & 1.1 & $(6,504)$ \\
\hline Turkey 2003 & 8.2 & 1.5 & 2.1 & 0.6 & $(3,902)$ \\
\hline Ukraine 2007 & 5.6 & 0.2 & 0.0 & -0.2 & $(4,116)$ \\
\hline Asia and Pacific & 14.0 & 1.3 & 2.7 & 1.4 & \\
\hline Bangladesh 2011 & 11.4 & 1.6 & 3.1 & 1.4 & $(16,635)$ \\
\hline Cambodia 2010 & 15.9 & 1.4 & 3.2 & 1.9 & $(11,626)$ \\
\hline India 2005-06 & 13.6 & 1.5 & 3.0 & 1.5 & $(93,089)$ \\
\hline Indonesia 2012 & 8.2 & 0.5 & 0.4 & -0.1 & $(33,465)$ \\
\hline Maldives 2009 & 12.8 & 1.1 & 1.4 & 0.3 & $(6,500)$ \\
\hline Nepal 2011 & 13.3 & 1.9 & 4.4 & 2.4 & $(9,608)$ \\
\hline Pakistan 2012-13 & 18.2 & 1.3 & 3.8 & 2.5 & $(12,937)$ \\
\hline Philippines 2008 & 13.4 & 2.2 & 4.2 & 2.0 & $(8,418)$ \\
\hline Timor-Leste 2009-10 & 27.5 & 0.7 & 3.5 & 2.7 & $(7,906)$ \\
\hline Vietnam 2002 & 9.2 & 0.9 & 1.7 & 0.8 & $(5,338)$ \\
\hline Latin America and Caribbean & 11.3 & 2.6 & 3.9 & 1.3 & \\
\hline Bolivia 2008 & 16.8 & 6.6 & 10.0 & 3.4 & $(10,162)$ \\
\hline Colombia 2010 & 6.3 & 1.1 & 1.4 & 0.3 & $(26,247)$ \\
\hline Dominican Republic 2007 & 8.2 & 1.0 & 1.5 & 0.5 & $(15,417)$ \\
\hline Guyana 2009 & 10.4 & 2.4 & 3.1 & 0.7 & $(2,920)$ \\
\hline Haiti 2012 & 20.5 & 5.3 & 8.0 & 2.7 & $(7,808)$ \\
\hline Honduras 2011-12 & 11.0 & 1.1 & 2.3 & 1.2 & $(12,847)$ \\
\hline Nicaragua 2001 & 11.0 & 2.9 & 4.3 & 1.4 & $(7,424)$ \\
\hline Peru 2012 & 8.5 & 2.1 & 3.1 & 1.0 & $(13,624)$ \\
\hline Unweighted averages & 21.0 & 2.0 & 3.4 & 1.5 & \\
\hline
\end{tabular}

NOTE: Regional estimates are unweighted averages of the country-specific estimates. 


\section{TABLE 5}

Percentage of married women aged 15-49 having unmet need if threshold for spacing need is reduced from two years to one, and differences from 2012-revised algorithm, by region and country, 60 countries, 2001-13

\begin{tabular}{|c|c|c|c|c|}
\hline Region/country and year of DHS survey & $\begin{array}{r}\text { Percent having } \\
\text { unmet need, 2012- } \\
\text { revised algorithm }\end{array}$ & $\begin{array}{r}\text { Percent having } \\
\text { unmet need, spacing } \\
\text { threshold reduced } \\
\text { to } 1 \text { year }\end{array}$ & $\begin{array}{r}\text { Differences in unmet } \\
\text { need due to limiting } \\
\text { spacing threshold to } 1 \\
\text { year }\end{array}$ & $\begin{array}{r}\text { Currently married } \\
\text { women }(\mathrm{N})\end{array}$ \\
\hline East and Southern Africa & 24.3 & 25.9 & 1.5 & \\
\hline Burundi 2010 & 32.4 & 34.3 & 1.9 & $(5,421)$ \\
\hline Ethiopia 2011 & 26.3 & 27.8 & 1.5 & $(10,287)$ \\
\hline Kenya 2008-09 & 25.6 & 27.1 & 1.5 & $(4,928)$ \\
\hline Lesotho 2009 & 23.3 & 24.6 & 1.3 & $(4,049)$ \\
\hline Madagascar 2008-09 & 19.0 & 20.4 & 1.4 & $(12,039)$ \\
\hline Malawi 2010 & 26.2 & 28.7 & 2.5 & $(15,528)$ \\
\hline Mozambique 2011 & 23.9 & 25.9 & 2.0 & $(9,332)$ \\
\hline Namibia 2006-07 & 20.7 & 22.1 & 1.4 & $(3,451)$ \\
\hline Rwanda 2010 & 20.8 & 21.6 & 0.8 & $(6,897)$ \\
\hline Swaziland 2006-07 & 24.7 & 25.9 & 1.2 & $(2,062)$ \\
\hline Tanzania 2010 & 22.3 & 24.2 & 1.9 & $(6,412)$ \\
\hline Uganda 2011 & 34.3 & 36.2 & 1.9 & $(5,418)$ \\
\hline Zambia 2007 & 26.6 & 27.8 & 1.2 & $(4,402)$ \\
\hline Zimbabwe 2010-11 & 14.6 & 15.7 & 1.1 & $(5,703)$ \\
\hline West and Central Africa & 26.8 & 29.2 & 2.4 & \\
\hline Benin 2011-12 & 32.6 & 34.1 & 1.5 & $(11,680)$ \\
\hline Burkina Faso 2010 & 24.5 & 28.2 & 3.7 & $(13,563)$ \\
\hline Cameroon 2011 & 23.5 & 26.3 & 2.8 & $(9,792)$ \\
\hline Chad 2004 & 20.6 & 23.6 & 3.0 & $(4,663)$ \\
\hline Congo (Brazzaville) 2011-12 & 18.4 & 19.4 & 1.0 & $(6,289)$ \\
\hline Congo (Democratic Republic) 2007 & 26.9 & 29.8 & 2.9 & $(6,622)$ \\
\hline Cote d'Ivoire 2011-12 & 27.1 & 29.7 & 2.6 & $(6,309)$ \\
\hline Gabon 2012 & 26.5 & 28.2 & 1.7 & $(4,475)$ \\
\hline Ghana 2008 & 35.7 & 37.2 & 1.5 & $(2,876)$ \\
\hline Guinea 2012 & 23.7 & 29.1 & 5.4 & $(6,726)$ \\
\hline Liberia 2007 & 35.7 & 36.9 & 1.2 & $(4,540)$ \\
\hline Mali 2006 & 27.6 & 30.3 & 2.7 & $(12,365)$ \\
\hline Niger 2012 & 16.0 & 20.2 & 4.2 & $(9,881)$ \\
\hline Nigeria 2008 & 20.2 & 22.6 & 2.4 & $(23,578)$ \\
\hline Sao Tome and Principe 2008-09 & 37.6 & 38.8 & 1.2 & $(1,718)$ \\
\hline Senegal 2010-11 & 30.1 & 31.8 & 1.7 & $(10,347)$ \\
\hline Sierra Leone 2008 & 28.4 & 30.2 & 1.8 & $(5,525)$ \\
\hline North Africa/West Asia/Europe & 13.5 & 14.6 & 1.0 & \\
\hline Albania 2008-09 & 12.9 & 13.3 & 0.4 & $(5,001)$ \\
\hline Armenia 2010 & 13.5 & 15.1 & 1.6 & $(3,626)$ \\
\hline
\end{tabular}




\begin{tabular}{|c|c|c|c|c|}
\hline Region/country and year of DHS survey & $\begin{array}{l}\text { Percent having } \\
\text { unmet need, 2012- } \\
\text { revised algorithm }\end{array}$ & $\begin{array}{r}\text { Percent having } \\
\text { unmet need, spacing } \\
\text { threshold reduced } \\
\text { to } 1 \text { year }\end{array}$ & $\begin{array}{r}\text { Differences in unmet } \\
\text { need due to limiting } \\
\text { spacing threshold to } 1 \\
\text { year }\end{array}$ & $\begin{array}{r}\text { Currently married } \\
\text { women }(\mathbf{N})\end{array}$ \\
\hline Azerbaijan 2006 & 15.4 & 16.3 & 0.9 & $(5,269)$ \\
\hline Egypt 2008 & 11.6 & 12.2 & 0.6 & $(15,396)$ \\
\hline Jordan 2012 & 11.7 & 12.8 & 1.1 & $(10,801)$ \\
\hline Kyrgyz Republic 2012 & 18.0 & 19.7 & 1.7 & $(5,256)$ \\
\hline Moldova 2005 & 11.4 & 11.9 & 0.5 & $(4,937)$ \\
\hline Morocco 2003-04 & 11.9 & 12.6 & 0.7 & $(8,782)$ \\
\hline Tajikistan 2012 & 22.9 & 25.9 & 3.0 & $(6,504)$ \\
\hline Turkey 2003 & 9.5 & 10.1 & 0.6 & $(3,902)$ \\
\hline Ukraine 2007 & 10.1 & 10.6 & 0.5 & $(4,116)$ \\
\hline Asia and Pacific & 19.2 & 20.5 & 1.3 & \\
\hline Bangladesh 2011 & 13.5 & 14.1 & 0.6 & $(16,635)$ \\
\hline Cambodia 2010 & 16.9 & 17.8 & 0.9 & $(11,626)$ \\
\hline India 2005-06 & 13.9 & 15.5 & 1.6 & $(93,089)$ \\
\hline Indonesia 2012 & 11.4 & 12.3 & 0.9 & $(33,465)$ \\
\hline Maldives 2009 & 28.6 & 31.7 & 3.1 & $(6,500)$ \\
\hline Nepal 2011 & 27.5 & 28.5 & 1.0 & $(9,608)$ \\
\hline Pakistan 2012-13 & 20.1 & 22.0 & 1.9 & $(12,937)$ \\
\hline Philippines 2008 & 22.0 & 22.8 & 0.8 & $(8,418)$ \\
\hline Timor-Leste 2009-10 & 31.5 & 33.6 & 2.1 & $(7,906)$ \\
\hline Vietnam 2002 & 6.6 & 6.9 & 0.3 & $(5,338)$ \\
\hline Latin America and Caribbean & 17.2 & 18.2 & 1.0 & \\
\hline Bolivia 2008 & 20.1 & 20.7 & 0.6 & $(10,162)$ \\
\hline Colombia 2010 & 8.0 & 8.5 & 0.5 & $(26,247)$ \\
\hline Dominican Republic 2007 & 11.1 & 12.3 & 1.2 & $(15,417)$ \\
\hline Guyana 2009 & 28.5 & 29.9 & 1.4 & $(2,920)$ \\
\hline Haiti 2012 & 35.3 & 36.2 & 0.9 & $(7,808)$ \\
\hline Honduras 2011-12 & 10.7 & 12.0 & 1.3 & $(12,847)$ \\
\hline Nicaragua 2001 & 14.6 & 15.8 & 1.2 & $(7,424)$ \\
\hline Peru 2012 & 9.3 & 9.9 & 0.6 & $(13,624)$ \\
\hline Unweighted averages & 21.2 & 22.8 & 1.6 & \\
\hline
\end{tabular}

NOTE: Regional estimates are unweighted averages of the country-specific estimates. 
TABLE 6

Percentage of married women aged 15-49 having unmet need, by region and country, according to the measure of the duration of postpartum amenorrhea, 60 countries, 2001-13

\begin{tabular}{|c|c|c|c|c|}
\hline Region/country and year of DHS survey & $\begin{array}{r}\text { Percent having } \\
\text { unmet need, 2012- } \\
\text { revised algorithm }\end{array}$ & $\begin{array}{r}\text { Percent having unmet } \\
\text { need, limiting } \\
\text { postpartum } \\
\text { amenorrhea to } 6 \\
\text { months }\end{array}$ & $\begin{array}{r}\text { Differences resulting } \\
\text { from limiting } \\
\text { postpartum } \\
\text { amenorrhea to } 6 \\
\text { months }\end{array}$ & $\begin{array}{r}\text { Currently } \\
\text { married women } \\
(\mathrm{N})\end{array}$ \\
\hline East and Southern Africa & 24.3 & 28.7 & 4.4 & \\
\hline Burundi 2010 & 32.4 & 43.0 & 10.6 & $(5,421)$ \\
\hline Ethiopia 2011 & 26.3 & 34.5 & 8.2 & $(10,287)$ \\
\hline Kenya 2008-09 & 25.6 & 28.7 & 3.1 & $(4,928)$ \\
\hline Lesotho 2009 & 23.3 & 24.6 & 1.3 & $(4,049)$ \\
\hline Madagascar 2008-09 & 19.0 & 25.0 & 6.0 & $(12,039)$ \\
\hline Malawi 2010 & 26.2 & 29.3 & 3.1 & $(15,528)$ \\
\hline Mozambique 2011 & 23.9 & 33.0 & 9.1 & $(9,332)$ \\
\hline Namibia 2006-07 & 20.7 & 21.9 & 1.2 & $(3,451)$ \\
\hline Rwanda 2010 & 20.8 & 25.0 & 4.2 & $(6,897)$ \\
\hline Swaziland 2006-07 & 24.7 & 26.1 & 1.4 & $(2,062)$ \\
\hline Tanzania 2010 & 22.3 & 26.9 & 4.6 & $(6,412)$ \\
\hline Uganda 2011 & 34.3 & 38.8 & 4.5 & $(5,418)$ \\
\hline Zambia 2007 & 26.6 & 30.1 & 3.5 & $(4,402)$ \\
\hline Zimbabwe 2010-11 & 14.6 & 15.4 & 0.8 & $(5,703)$ \\
\hline West and Central Africa & 26.8 & 33.1 & 6.4 & \\
\hline Benin 2011-12 & 32.6 & 37.9 & 5.3 & $(11,680)$ \\
\hline Burkina Faso 2010 & 24.5 & 36.3 & 11.8 & $(13,563)$ \\
\hline Cameroon 2011 & 23.5 & 28.8 & 5.3 & $(9,792)$ \\
\hline Chad 2004 & 20.6 & 29.4 & 8.8 & $(4,663)$ \\
\hline Congo (Brazzaville) 2011-12 & 18.4 & 22.0 & 3.6 & $(6,289)$ \\
\hline Congo (Democratic Republic) 2007 & 26.9 & 32.0 & 5.1 & $(6,622)$ \\
\hline Cote d'Ivoire 2011-12 & 27.1 & 33.8 & 6.7 & $(6,309)$ \\
\hline Gabon 2012 & 26.5 & 27.8 & 1.3 & $(4,475)$ \\
\hline Ghana 2008 & 35.7 & 39.6 & 3.9 & $(2,876)$ \\
\hline Guinea 2012 & 23.7 & 32.5 & 8.8 & $(6,726)$ \\
\hline Liberia 2007 & 35.7 & 41.1 & 5.4 & $(4,540)$ \\
\hline Mali 2006 & 27.6 & 35.1 & 7.5 & $(12,365)$ \\
\hline Niger 2012 & 16.0 & 25.9 & 9.9 & $(9,881)$ \\
\hline Nigeria 2008 & 20.2 & 29.4 & 9.2 & $(23,578)$ \\
\hline Sao Tome and Principe 2008-09 & 37.6 & 38.7 & 1.1 & $(1,718)$ \\
\hline Senegal 2010-11 & 30.1 & 37.4 & 7.3 & $(10,347)$ \\
\hline Sierra Leone 2008 & 28.4 & 35.3 & 6.9 & $(5,525)$ \\
\hline North Africa/West Asia/Europe & 13.5 & 14.2 & 0.7 & \\
\hline Albania 2008-09 & 12.9 & 12.9 & 0.0 & $(5,001)$ \\
\hline Armenia 2010 & 13.5 & 13.7 & 0.2 & $(3,626)$ \\
\hline
\end{tabular}




\begin{tabular}{|c|c|c|c|c|}
\hline Region/country and year of DHS survey & $\begin{array}{l}\text { Percent having } \\
\text { unmet need, 2012- } \\
\text { revised algorithm }\end{array}$ & $\begin{array}{r}\text { Percent having unmet } \\
\text { need, limiting } \\
\text { postpartum } \\
\text { amenorrhea to } 6 \\
\text { months }\end{array}$ & $\begin{array}{r}\text { Differences resulting } \\
\text { from limiting } \\
\text { postpartum } \\
\text { amenorrhea to } 6 \\
\text { months }\end{array}$ & $\begin{array}{r}\text { Currently } \\
\text { married women } \\
(\mathrm{N})\end{array}$ \\
\hline Azerbaijan 2006 & 15.4 & 15.6 & 0.2 & $(5,269)$ \\
\hline Egypt 2008 & 11.6 & 12.0 & 0.4 & $(15,396)$ \\
\hline Jordan 2012 & 11.7 & 11.8 & 0.1 & $(10,801)$ \\
\hline Kyrgyz Republic 2012 & 18.0 & 21.1 & 3.1 & $(5,256)$ \\
\hline Moldova 2005 & 11.4 & 11.7 & 0.3 & $(4,937)$ \\
\hline Morocco 2003-04 & 11.9 & 12.1 & 0.2 & $(8,782)$ \\
\hline Tajikistan 2012 & 22.9 & 25.2 & 2.3 & $(6,504)$ \\
\hline Turkey 2003 & 9.5 & 9.7 & 0.2 & $(3,902)$ \\
\hline Ukraine 2007 & 10.1 & 10.4 & 0.3 & $(4,116)$ \\
\hline Asia and Pacific & 19.2 & 21.0 & 1.8 & \\
\hline Bangladesh 2011 & 13.5 & 14.6 & 1.1 & $(16,635)$ \\
\hline Cambodia 2010 & 16.9 & 19.6 & 2.7 & $(11,626)$ \\
\hline India 2005-06 & 13.9 & 15.9 & 2.0 & $(93,089)$ \\
\hline Indonesia 2012 & 11.4 & 11.9 & 0.5 & $(33,465)$ \\
\hline Maldives 2009 & 28.6 & 29.5 & 0.9 & $(6,500)$ \\
\hline Nepal 2011 & 27.5 & 29.4 & 1.9 & $(9,608)$ \\
\hline Pakistan 2012-13 & 20.1 & 21.7 & 1.6 & $(12,937)$ \\
\hline Philippines 2008 & 22.0 & 23.0 & 1.0 & $(8,418)$ \\
\hline Timor-Leste 2009-10 & 31.5 & 37.0 & 5.5 & $(7,906)$ \\
\hline Vietnam 2002 & 6.6 & 7.6 & 1.0 & $(5,338)$ \\
\hline Latin America and Caribbean & 17.2 & 18.1 & 0.9 & \\
\hline Bolivia 2008 & 20.1 & 21.4 & 1.3 & $(10,162)$ \\
\hline Colombia 2010 & 8.0 & 8.1 & 0.1 & $(26,247)$ \\
\hline Dominican Republic 2007 & 11.1 & 11.3 & 0.2 & $(15,417)$ \\
\hline Guyana 2009 & 28.5 & 29.4 & 0.9 & $(2,920)$ \\
\hline Haiti 2012 & 35.3 & 38.0 & 2.7 & $(7,808)$ \\
\hline Honduras 2011-12 & 10.7 & 11.2 & 0.5 & $(12,847)$ \\
\hline Nicaragua 2001 & 14.6 & 15.3 & 0.7 & $(7,424)$ \\
\hline Peru 2012 & 9.3 & 9.7 & 0.4 & $(13,624)$ \\
\hline Unweighted averages & 21.2 & 24.6 & 3.4 & \\
\hline
\end{tabular}

NOTE: Regional estimates are unweighted averages of the country-specific estimates. 